\title{
Dust aerosols over India and adjacent continents retrieved using METEOSAT infrared radiance Part II: quantification of wind dependence and estimation of radiative forcing
}

\author{
S. Deepshikha, S. K. Satheesh, and J. Srinivasan \\ Centre for Atmospheric and Oceanic Sciences, Indian Institute of Science, Bangalore-560 012, India
}

Received: 20 January 2005 - Revised: 2 December 2005 - Accepted: 21 December 2005 - Published: 7 March 2006

\begin{abstract}
Long-range transport of continental dust makes these particles a significant constituent even at locations far from their sources. It is important to study the temporal variations in dust loading over desert regions and the role of meteorology, in order to assess its radiative impact. In this paper, infrared radiance $(10.5-12.5 \mu \mathrm{m})$, acquired by the METEOSAT-5 satellite ( $\sim 5-\mathrm{km}$ resolution) during 1999 and 2003 was used to quantify wind dependence of dust aerosols and to estimate the radiative forcing. Our analysis shows that the frequency of occurrence of dust events was higher during 2003 compared to 1999. Since the dust production function depends mainly on the surface wind speed over regions which are dry and without vegetation, the role of surface wind on IDDI was examined in detail. It was found that an increase of IDDI with wind speed was nearly linear and the rate of increase in IDDI with surface wind was higher during 2003 compared to 1999. It was also observed that over the Indian desert, when wind speed was the highest during monsoon months (June to August), the dust production rate was lower because of higher soil moisture (due to monsoon rainfall). Over the Arabian deserts, when the wind speed is the highest during June to August, the dust production rate is also highest, as soil moisture is lowest during this season. Even though nothing can be said precisely on the reason why 2003 had a greater number of dust events, examination of monthly mean soil moisture at source regions indicates that the occurrence of high winds simultaneous with high soil moisture could be the reason for the decreased dust production efficiency in 1999. It appears that the deserts of Northwest India are more efficient dust sources compared to the deserts of Saudi Arabia and Northeast Africa (excluding Sahara). The radiative impact of dust over various source regions is estimated, and the regionally and annually averaged top of the atmosphere dust radiative forcing (short wave, clear-sky and over land) over the entire study region $\left(0-35^{\circ} \mathrm{N} ; 30^{\circ}-100^{\circ} \mathrm{E}\right)$ was in the range of -0.9 to $+4.5 \mathrm{~W} \mathrm{~m}^{-2}$. The corresponding
\end{abstract}

Correspondence to: S. K. Satheesh

(satheesh@ caos.iisc.ernet.in) values at the surface were in the range of -10 to $-25 \mathrm{~W} \mathrm{~m}^{-2}$. Our studies demonstrate that neglecting the diurnal variation of dust can cause errors in the estimation of long wave dust forcing by as much as 50 to $100 \%$, and nighttime retrieval of dust can significantly reduce the uncertainties. A method to retrieve dust aerosols during nighttime is proposed. The regionally and annually averaged long wave dust radiative forcing was $+3.4 \pm 1.6 \mathrm{~W} \mathrm{~m}^{-2}$.

Keywords. Atmospheric composition and structure (Aerosols and particles; Transmission and scattering of radiation) - History of Geophysics (Atmospheric sciences)

\section{Introduction}

Soil derived particles are among the largest aerosols, with radii ranging from less than $0.1 \mu \mathrm{m}$ to $\sim 100 \mu \mathrm{m}$ (Kalu, 1979; Arimoto et al., 1995, 1997; Tanré et al., 2001; Prospero et al., 2002). Particles larger than $5 \mu \mathrm{m}$ are present only in source regions but particles in the size range 0.1 to $5 \mu \mathrm{m}$ are transported to large distances from their sources (Arimoto, 2001; Prospero, 2001, 2003). The long-range transport of continental dust by the combined action of convection currents and general circulation make these particles a significant constituent even at locations far from their sources (Arimoto et al., 2001; Zender et al., 2003; Ginoux et al., 2004). When the wind pattern is favourable dust aerosols are transported over the Atlantic Ocean and the Arabian Sea from the Sahara and Arabian deserts, respectively, to reach far ocean locations, thousands of kilometres away from their sources. There have been a number of investigations in the literature regarding the transport of aerosols from the continents to the ocean (Bergametti et al., 1989; Arimoto et al., 1995; Gong et al., 2003; Zender et al., 2003). Some of these authors found the existence of Saharan dust even over the remote areas of the Atlantic and Pacific Oceans (d'Almeida et al., 1991). Prospero et al. (1970) traced the origin of a dust event at Barbados (an island location in the Atlantic) to West Africa, with 
a transport time of $\sim 5$ days. The chemical analysis of marine aerosol samples collected over the Atlantic Ocean revealed an African source (Bergametti et al., 1989). The major source of mineral dust in Africa is the Sahara. Junge (1972) estimated that 60 to $200 \mathrm{Tg}$ of Saharan dust is generated over the Sahara and is transported each year, whereas Duce et al. (1991) estimated that $\sim 220 \mathrm{Tg}$ of mineral dust is transported to the North Atlantic each year. Thus, it is important to quantify the dust loading over desert regions, in order to assess its impact over other regions including oceans.

Many global models do not accurately simulate regional distribution of dust due to their low grid resolution and the inaccuracy of dust source function (Zender et al., 2003; Tegen et al., 2004). To accurately predict the impact of dust on the climate the spatial and temporal distribution of dust is essential (Tanré et al., 2003) The dust emission is usually calculated depending on the soil moisture, surface wind speed and surface soil conditions (such as vegetated or bare soil) (Tegen and Miller, 1998; Miller et al., 2004). The regional characteristics of dust depend on these parameters. However, regional characteristics of dust production and its dependence on meteorological parameters are poorly understood (Seinfeld et al., 2004). Previous investigations on dust aerosols have shown that dust production depends on the surface wind speed (Gillette et al., 1974). Recent studies have shown that a fraction of the atmospheric dust originates from anthropogenic activities (Satheesh and Moorthy, 2005). Thus, it is essential to separate the anthropogenic component from the naturally originated dust, due to changes in meteorological conditions.

In Part I of this paper, satellite measured infrared (IR) radiance acquired from METEOSAT-5 in the 10.5 to $12.5-\mu \mathrm{m}$ wavelength band (at $\sim 5-\mathrm{km}$ resolution) was used to retrieve dust aerosol properties. The approach is based on Tanré and Legrand (1991) and Legrand et al. (1994, 2001). An InfraRed Brightness Temperature (IRBT) depression caused by the presence of dust aerosols in the atmosphere was used as an index of dust load and is called the Infrared Difference Dust Index (IDDI). The IDDI images were created using Radiometric Counts (RC) from METEOSAT-5. Radiometric Counts were converted into radiance and then radiance data were converted into brightness temperature (IRBT) using an inverse Planck Function. This IRBT formed the "original image", which contains all the radiative information about the surface and the atmosphere. The next step was to create "reference image" representing clear-sky conditions for consecutive, non-overlapping periods, whose durations are short enough to eliminate the seasonal effects but long enough to ensure that the clear-sky or near clear-sky conditions exist for at least one measurement for each pixel. The purpose of the "reference image" is to separate the land effect from the "original image". A 15-day reference period was used. The "difference image" represents features of clouds and dust patterns separated from the permanent surface features. This was obtained by subtracting the individual day "original image" (or IRBT) from the "reference image" for that period. The "difference image" after cloud-screening (using spatial coherence method) provided the IDDI image.

In Part I, regional characteristics of dust aerosols during two years, 1999 and 2003, was discussed. It was observed that dust activity starts by March over the Indian deserts, as well as over the deserts of Africa and the Arabian regions. The IDDI reaches a maximum during the period between May to August. The IDDI values have been compared with another year (i.e. 2003), with a large number of dust storms reported by meteorological departments based on visibility data. During the dry season, the magnitude of the monthly average IDDI during 2003 was slightly higher than that of 1999. Monthly mean IDDI was in the range from 4 to 9 over the Indian deserts, as well as over the deserts of Africa. The maximum IDDI during a month was as high as in the range from 6 to 18. Large IDDI was observed even over vegetated regions (such as the vegetated part of Africa and central India), attributed to the presence of transported dust from nearby deserts. In this paper (Part II), we examine in detail the role of surface wind speed on IDDI over regions which are dry and without vegetation. Estimates of short wave dust radiative forcing were made. We also present a method to retrieve dust aerosol properties during the nighttime and discuss its implications to long wave radiative forcing.

\section{Results and discussion}

\subsection{Quantification of wind dependence of IDDI}

The discussions in the Companion Paper have shown that dust load during 2003 was slightly higher compared to 1999. In order to examine this aspect in more detail, five out of seven regions in Part I were considered. These are Saudi Arabia-I, Saudi Arabia-II, Somalia, Rajasthan and NE Africa. Thus, the regions considered include four dry (and without vegetation) and one vegetated region. While monthly mean IDDI values are representative of the average dust load, it does not provide any information on the number of dust events. It is possible that a large number of moderate dust events and fewer intense dust events result in similar monthly mean IDDI. In these two cases, however, the radiative impact of dust is different because in one case, there is a persistent dust load, whereas in the second case the dust load is shooting up only occasionally. Thus, it is essential to examine the number of dust events. The best and most common way of defining a dust event is by applying a threshold value for IDDI (Leon and Legrand, 2003). In our study we have used an IDDI value of $8 \mathrm{~K}$ to define a dust event. A region which experienced an IDDI of $8 \mathrm{~K}$ or more (on a daily basis) was considered as having encountered a dust event. The percentage of occurrence of IDDI $>8 \mathrm{~K}$ experienced in the Saudi Arabian region (SA-1; Region-1 in Fig. 9 of Part I) for all of 1999 and 2003 is shown in Fig. 1 (top panel). It can be seen that in January to May, the frequency of occurrence of dust events was significantly high during 2003 compared to 1999. After May, there was no systematic difference. It is known that the most fundamental parameter 


\section{Percentage of Occurr ence with IDDI $>8 \mathrm{~K}$ and} Wind Speed $>5 \mathrm{~m} \mathrm{~s}^{-1}$ over $\mathrm{S}$ Arabian Region
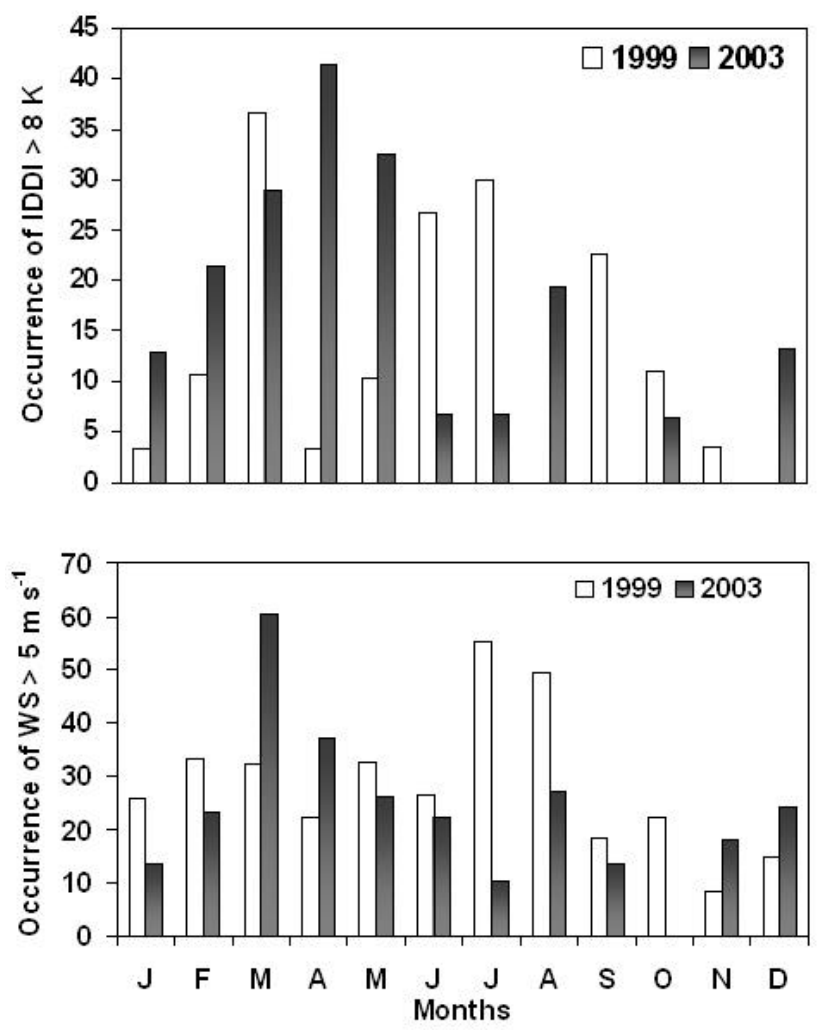

Fig. 1. The percentage of occurrence with IDDI $>8 \mathrm{~K}$ and wind speed $\mathrm{U}>5 \mathrm{~m} \mathrm{~s}^{-1}$ over Saudi Arabia.

on which the dust production rate depends is surface wind speed (Gillette, 1979). To examine the role of surface winds (U), we have also plotted in Fig. 1 (bottom panel), the frequency of occurrence of high winds $\left(\mathrm{U}>5 \mathrm{~m} \mathrm{~s}^{-1}\right)$. The wind speed data was obtained from NCEP/NCAR reanalysis (described in Part I). We have used $5 \mathrm{~m} \mathrm{~s}^{-1}$ because this is close to the mean wind observed over the study region. Similarly, IDDI of $8 \mathrm{~K}$ is close to the mean IDDI observed over the study region. While there were no systematic differences in the frequency of occurrence of high winds between the two years, March and April 2003 experienced a much higher frequency of high winds compared to the corresponding months in 1999. The frequency of occurrence of high winds corresponding to Saudi Arabia-I, NE Africa and Rajasthan is given in Table 1.

The percentage of occurrence of IDDI $>8 \mathrm{~K}$ experienced in NE Africa for all months of 1999 and 2003 is shown in Fig. 2 (top panel). It can be seen that in more than six months, the frequency of occurrence of dust events was significantly high during 2003 compared to 1999 . The frequency of occurrence of high winds is also shown in Fig. 2 (bottom panel). There was practically no high wind except in February, April and May. The only periods when this region experienced high winds were February and May 1999.
Table 1. Comparison of Frequency of Occurrence of Wind (\%).

\begin{tabular}{|l|l|l|l|l|l|l|}
\hline \multirow{2}{*}{ Month } & \multicolumn{2}{|l|}{ Saudi Arabia } & \multicolumn{2}{l|}{ NE Africa } & \multicolumn{2}{l|}{ Rajasthan } \\
\cline { 2 - 7 } & 1999 & 2003 & 1999 & 2003 & 1999 & 2003 \\
\hline Jan & 26.0 & 13.5 & 0.0 & 0.0 & 0.0 & 0.0 \\
\hline Feb & 33.4 & 23.4 & 24.2 & 0.0 & 3.5 & 13.8 \\
\hline Mar & 32.5 & 60.3 & 0.0 & 0.0 & 30.1 & 10.0 \\
\hline Apr & 22.5 & 37.3 & 06 & 0.0 & 50.3 & 6.7 \\
\hline May & 32.6 & 26.3 & 03 & 0.0 & 60.2 & 33.3 \\
\hline Jun & 26.7 & 22.4 & 0.0 & 0.0 & 63.3 & 43.3 \\
\hline Jul & 55.4 & 10.4 & 0.0 & 0.0 & 60.0 & 20.0 \\
\hline Aug & 49.5 & 27.3 & 0.0 & 0.0 & 65.4 & 50.0 \\
\hline Sep & 18.6 & 13.6 & 0.0 & 0.0 & 30.4 & 13.3 \\
\hline Oct & 22.4 & 0.0 & 0.0 & 0.0 & 0.0 & 0.0 \\
\hline Nov & 8.3 & 18.2 & 0.0 & 0.0 & 3.5 & 0.0 \\
\hline Dec & 14.8 & 24.2 & 0.0 & 0.0 & 0.0 & 0.0 \\
\hline Average & 28.6 & 23.1 & 2.8 & 0.0 & 30.5 & 15.9 \\
\hline
\end{tabular}

A similar analysis was made for the Rajasthan region, as well. The percentage of occurrence of IDDI $>8 \mathrm{~K}$ experienced at Rajasthan for all of 1999 and 2003 is shown in Fig. 3 (top panel). Again, the frequency of occurrence of dust events was significantly high during 2003 compared to 1999. The frequency of occurrence of high winds (Fig. 3, bottom panel), however, shows that in 1999 the occurrences of high wind were greater. In summary, the above analysis indicates that even though the occurrence of dust events was more in 2003 compared to 1999, there were no systematic differences in the occurrences of surface wind speed between the two years. It may be noted, however, from Figs. 1, 2 and 3 , that except over NE Africa, the seasonal changes in frequency of the occurrence of high wind speed and IDDI are somewhat correlated. For example, in Saudi Arabia, when a high IDDI peak occurred around March-April 2003, the wind speed also showed a similar pattern. In 1999, however, there was no such correlation. In Rajasthan, the occurrence of a high IDDI and the wind speed shows a similar pattern in 2003. In 1999, however, there was no such correlation. Thus, it is certain that at least in 2003 surface winds have played a role in the observed variations in dust load. To examine this aspect, we show in Figs. 4, 5 and 6 the daily IDDI and wind speed for Saudi Arabia-I, NE Africa and Rajasthan, respectively. The solid lines represent a 10-day running average.

The following can be noted from Figs. 4 to 6 :

- In Saudi Arabia, IDDI and surface winds show somewhat similar variations.

- In NE Africa, IDDI and surface winds show opposite trends in both years.

- In Rajasthan, IDDI and surface winds show opposite trends in 1999 while somewhat similar variations in 2003. 

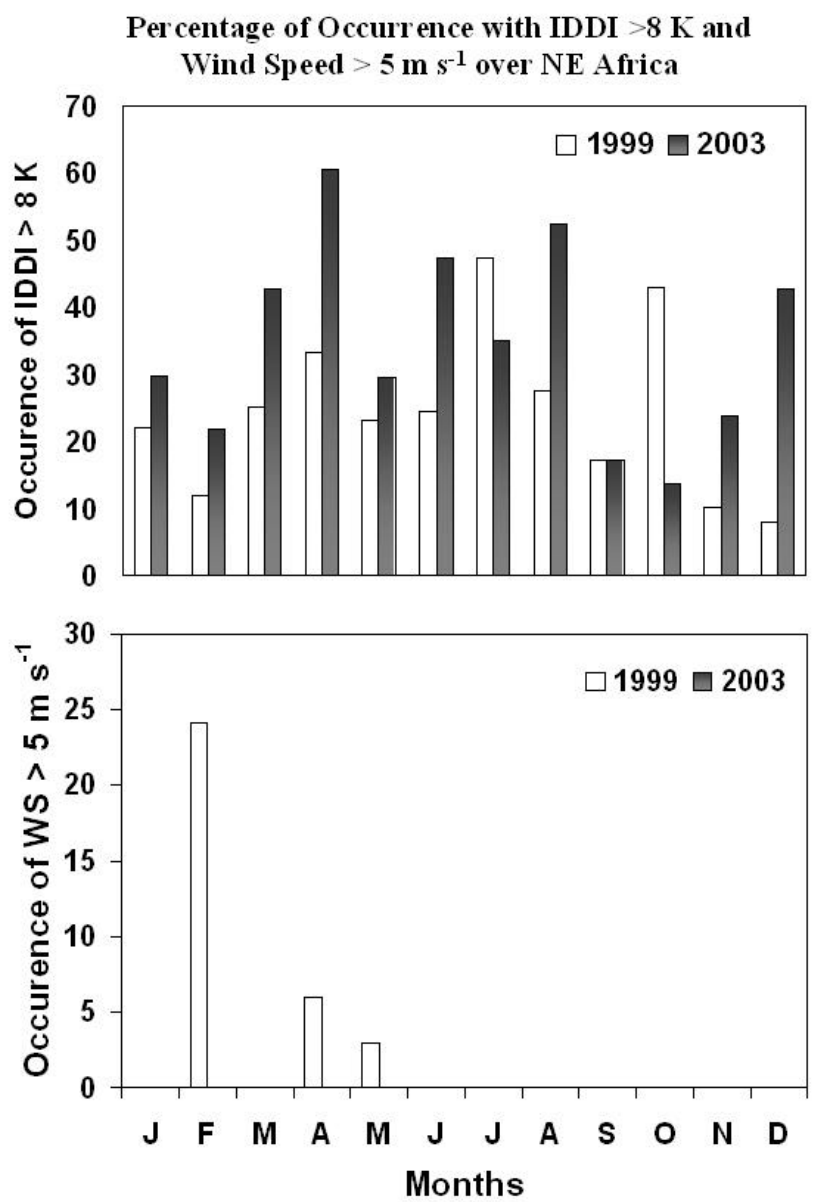

Fig. 2. The percentage of occurrence with IDDI $>8 \mathrm{~K}$ and wind speed $\mathrm{U}>5 \mathrm{~m} \mathrm{~s}^{-1}$ over NE Africa.

To quantify these aspects we show scatter plots of daily IDDI versus wind speed for Saudi Arabia-I, NE Africa and Rajasthan for 1999 and 2003 (Figs. 7, 8 and 9). We have used a threshold wind of $0.5 \mathrm{~m} \mathrm{~s}^{-1}$ for studying dust production, since even at low winds dust aerosols are produced. Investigations in the past have reported that the threshold wind speed required for dust production starts at $4 \mathrm{~m} \mathrm{~s}^{-1}$ (Helgren and Prospero, 1987; Nickling and Gillies, 1989). However, studies carried out later have shown that wind speed as low as $0.5 \mathrm{~m} \mathrm{~s}^{-1}$ is capable of transporting the mineral dust particles in the atmosphere as large as $2 \mu \mathrm{m}$ in size (McTainsh, 1980; d'Almeida et al., 1991). Fitzgerald (1991) has shown that threshold wind speed required for sea salt production over the ocean is $3 \mathrm{~m} \mathrm{~s}^{-1}$. They found that the threshold wind speed needed for sea salt production is much larger compared to the threshold for dust production over the deserts. The reason is that over deserts loose dust is available at the surface for transport by winds while over oceans droplets need to be produced first before they become air-borne. Thus, $0.5 \mathrm{~m} \mathrm{~s}^{-1}$ appears more reasonable as a threshold for dust production. However, we have attempted a higher value of the threshold, as well (discussed later). The purpose of the IDDI versus wind plot is to study the rate of increase of IDDI with wind.

\section{Percentage of Occurr ence with IDDI $>8 \mathrm{~K}$ and Wind Speed $>5 \mathrm{~m} \mathrm{~s}^{-1}$ over Rajasthan}
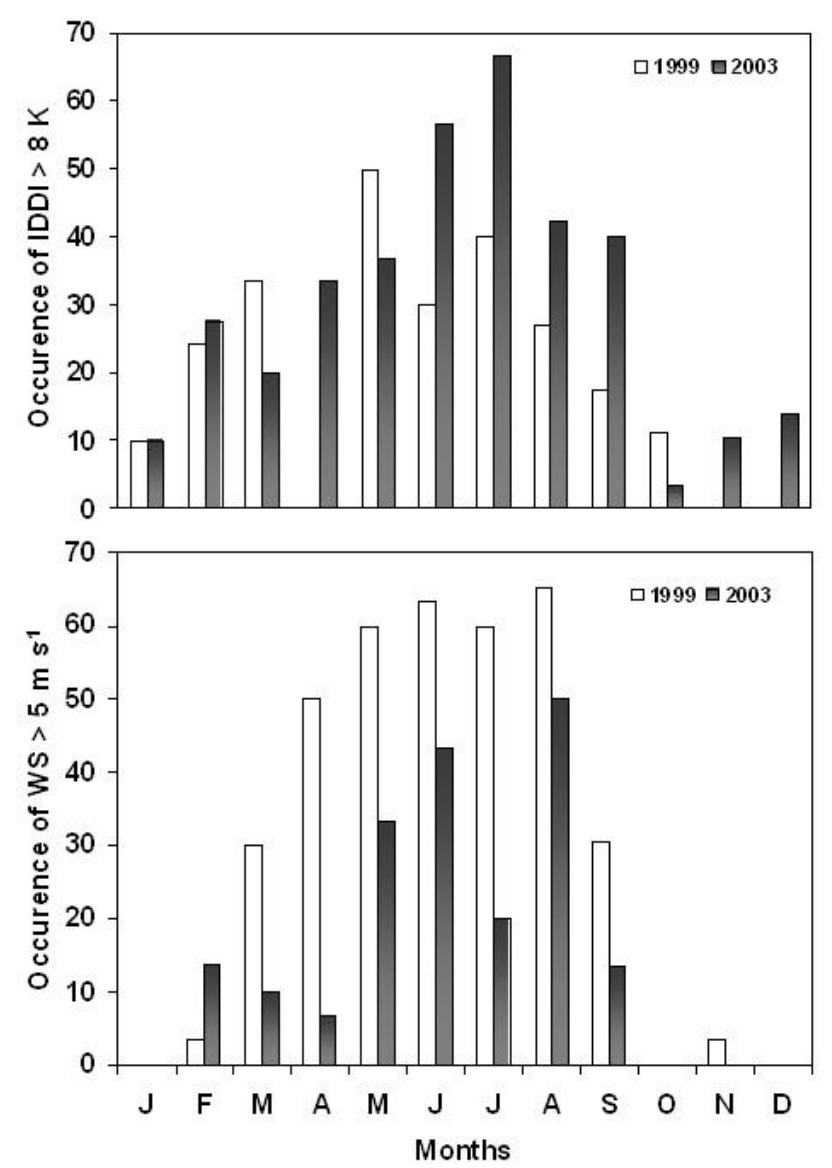

Fig. 3. The percentage of occurrence with IDDI $>8 \mathrm{~K}$ and wind speed $\mathrm{U}>5 \mathrm{~m} \mathrm{~s}^{-1}$ over Rajasthan.

Here (Figs. 7, 8 and 9), we did not use IDDI below $2 \mathrm{~K}$, since the influence of other factors, such as water vapour, can be as large as 2 K. In Figs. 7, 8 and 9, we did not use IDDI from moist season. Similar analysis was carried out for Somalia and Saudi Arabia-II (both dry regions), as well. The equation representing the linear fitted line is also shown in the corresponding figures. Regression coefficients are provided in Table 2, corresponding to five regions. Here, the slope of the line represents the rate of increase of IDDI with an increase in wind speed, and the intercept is a measure of the background dust load. In addition to linear fit, we have also made exponential fit to IDDI versus wind variation. These coefficients are also provided (in brackets) in Table 2.

The following can be noted from Figs. 7 to 9 and Table 2 . The points with a vertical bar represent bin average (with bin width of $1 \mathrm{~m} \mathrm{~s}^{-1}$ ) and the vertical bar represents the standard deviation.

- The IDDI and wind speed show a high correlation in Saudi Arabia-I, Saudi Arabia-II, Somalia and Rajasthan, but not in NE Africa. One possibility is that while the first four regions are the dust sources, the 

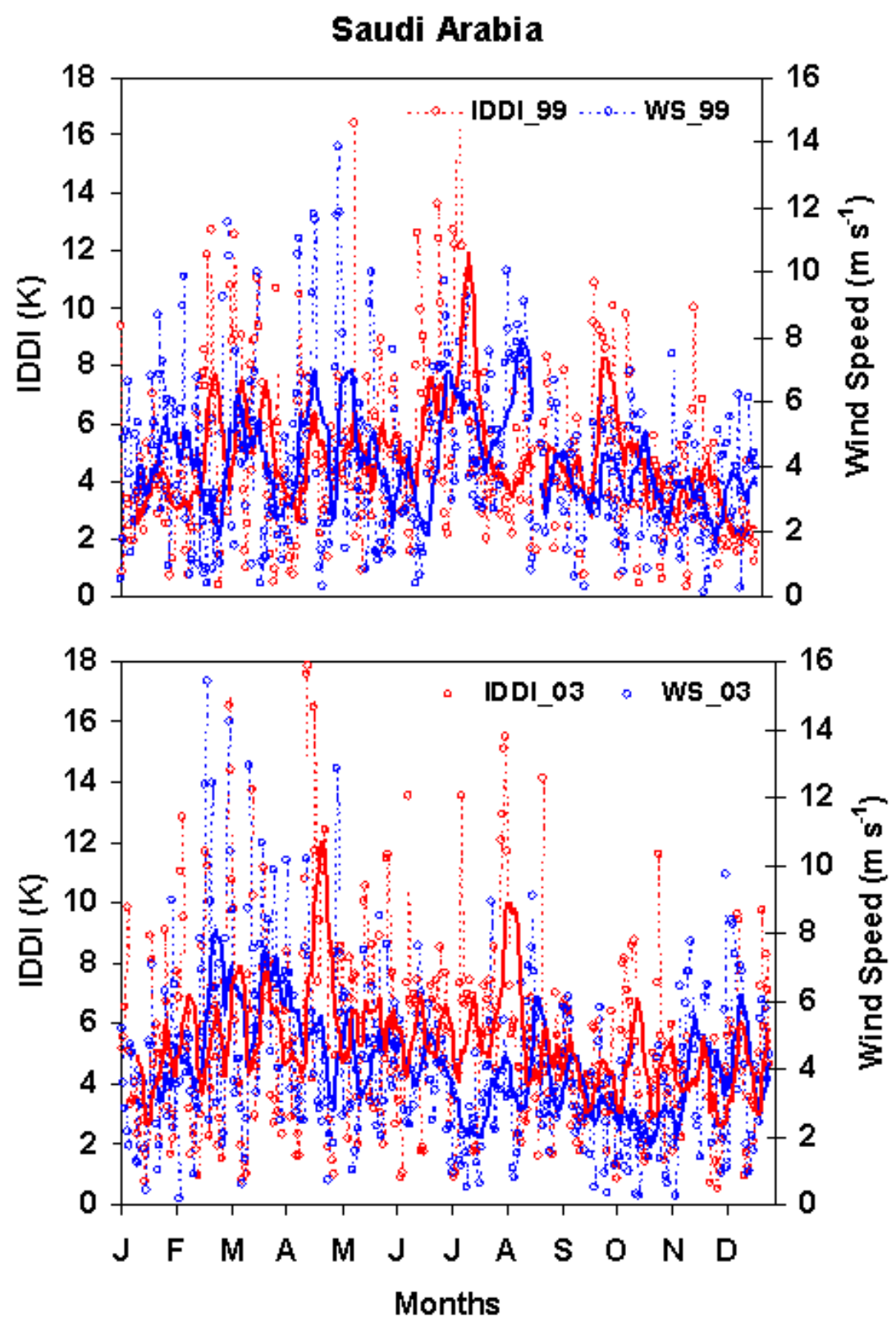

Fig. 4. Daily IDDI and wind speed (dashed lines) for Saudi Arabia. Solid line represents 10-day running average.

large dust load experienced in NE Africa could be due to transported dust, not locally produced dust. Vegetation index maps discussed in Part I support this conclusion.

- The rate of increase of IDDI with wind speed was higher during 2003 compared to 1999 in Saudi Arabia-I, Saudi Arabia-II, Somalia and Rajasthan.

- It appears that Rajasthan is a more efficient dust source than Saudi Arabia, as can be inferred from the slope of the fitted line (Table 2). The slope was $1.58 \mathrm{~K} \mathrm{~s} \mathrm{~m}^{-1}$ for the Rajasthan region (during 2003) while it was $0.69 \mathrm{~K} \mathrm{~s} \mathrm{~m}^{-1}$ (during 2003) for the Saudi Arabian region. One reason for this could be due to the fact that while Saudi Arabia is always dry (as seen from soil moisture distribution shown in Part I), the Rajasthan region experiences periodic dry and wet conditions due to monsoon rainfall. This might enhance the grinding process and result in more loose soil at the surface. The slope (Table 2$)$ was still lower $\left(0.39 \mathrm{~K} \mathrm{~s} \mathrm{~m}^{-1}\right)$ for Somalia.

- The IDDI corresponding to background dust (as inferred from the intercept of the fitted line) was in the range of 3 to $5 \mathrm{~K}$ in the case when all five regions were considered.

We have also attempted a higher threshold $\left(4 \mathrm{~m} \mathrm{~s}^{-1}\right)$ for dust production (in the case of Saudi Arabia-I and Rajasthan), as suggested earlier by a few investigators (e.g. Helgren and 


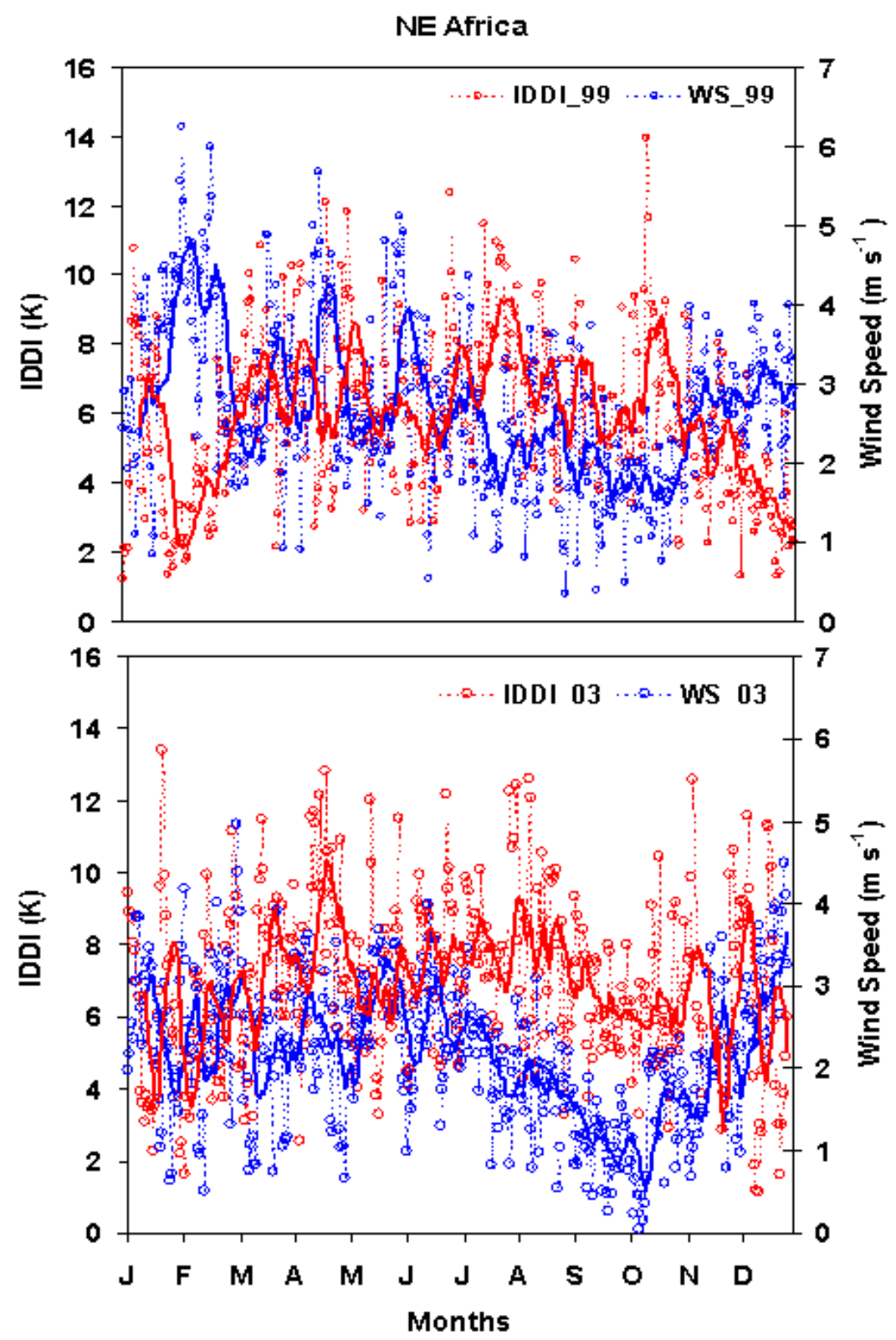

Fig. 5. Daily IDDI and wind speed (dashed lines) for NE Africa. Solid line represents 10-day running average.

Prospero, 1987; Nickling and Gillies, 1989). The slope (linear fit) for 1999 (and 2003) for Saudi Arabia-I was 0.88 (1.4) and that for Rajasthan was 1.1 (1.9).

Another factor which controls the dust production rate is the soil moisture distribution. The difference in soil moisture (from NCEP/NCAR) between 2003 and 1999 for all months is shown in Figs. 10 and 11. Even though nothing can be said precisely, examination of the individual region's monthly mean soil moisture distribution in both years indicates that the occurrence of high winds simultaneous with high soil moisture (could be due to rainfall) could be the reason for a decreased dust production efficiency in 1999.

\subsection{Short-wave radiative forcing due to dust}

For absorbing aerosols like dust, radiative forcing at the surface differs substantially from its value at the Top Of the atmosphere (TOA) and the climate response depends not only upon the TOA forcing, but its difference with respect to the surface value, which represents radiative heating within the atmosphere (Satheesh and Ramanathan, 2000; Miller et al., 2004). Surface forcing alters evaporation and the hydrologic cycle. Studies have shown that while global evaporation and precipitation are reduced in response to surface radiative forcing by dust, precipitation increases locally over desert regions, so that dust emission can act as a negative feedback to desertification (Miller et al., 2004). 

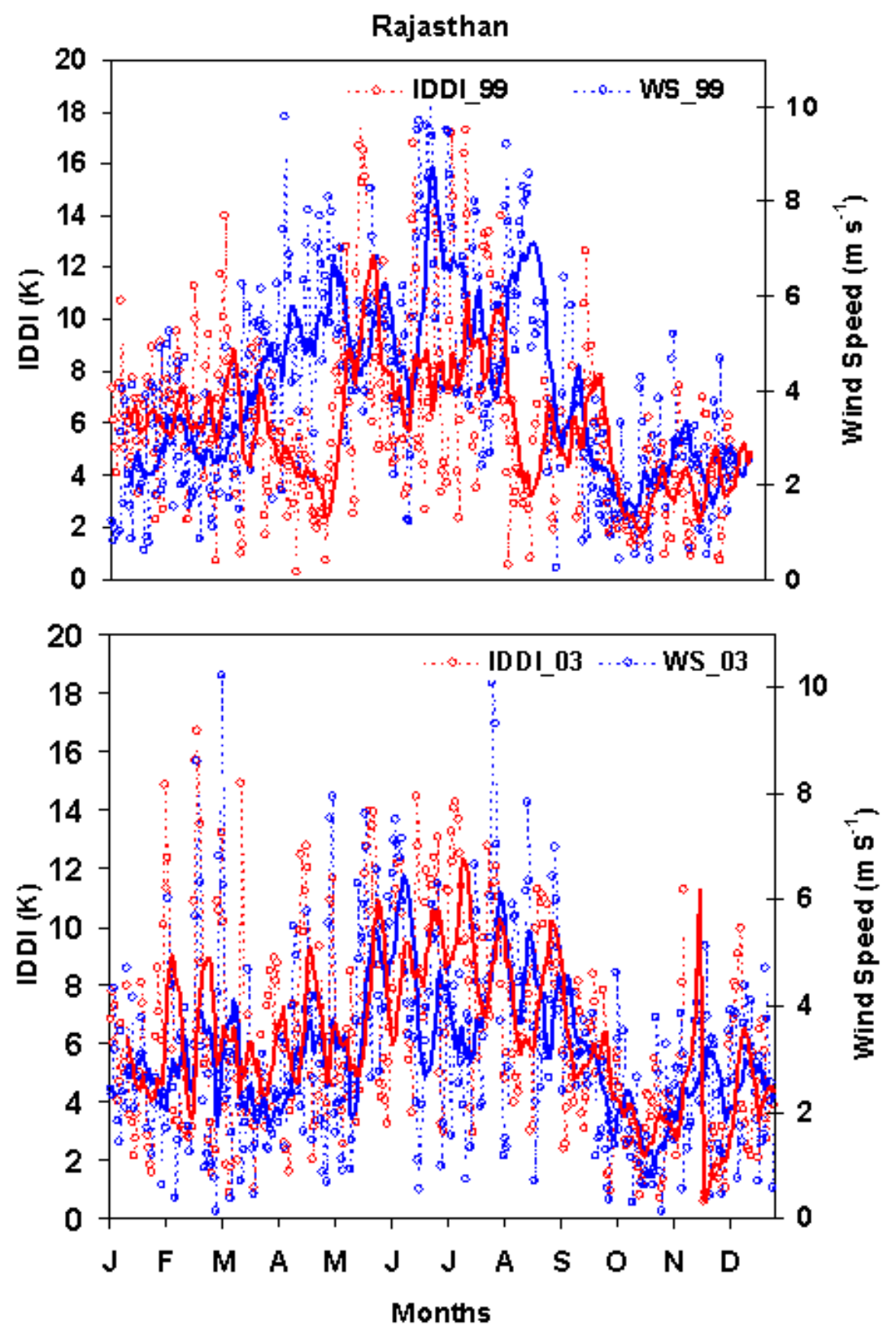

Fig. 6. Daily IDDI and wind speed (dashed lines) for Rajasthan. Solid line represents 10-day running average.

We have examined the impact of dust aerosols and other aerosol species on infrared radiation in Part I of this paper, using a four-component aerosol system consists of mineral dust, sea salt, soot and sulphate. The optical properties of different aerosol species were obtained from Hess et al. (1998) and Kaufman et al. (2001). We have shown that when the dust optical depth at $0.5 \mu \mathrm{m}$ is 1.0 , the dust optical depth in IR (at $11 \mu \mathrm{m}$ ) is around 0.33, which is higher than all other species. The second highest contributor to infrared optical depth was sea salt, which has an optical depth of 0.06 at $11 \mu \mathrm{m}$, which is much lower compared to the dust optical depth. The sulphate and soot have much lower optical depths at $11 \mu \mathrm{m}$. This demonstrates that the mineral dust is the only aerosol species over land regions which can influence the infrared radiation significantly.

Dust aerosols are significant contributors to radiative warming below $500 \mathrm{mb}$, due to short-wave absorption (Mohalfi et al., 1998; Alpert et al., 1998; Miller and Tegen, 1999). Typically, dust approximately doubles the short-wave radiation absorption under clear-sky conditions (Tegen and Miller, 1998). Tegen and Fung (1994) have shown that dust from disturbed soil causes a net cooling at the surface, accompanied by an increase in atmospheric heating. The reduction of solar radiation reaching the Earth's surface, as a result of scattering and absorption by dust aerosols, reduces the sensible heat flux (Satheesh and Ramanathan, 2000). This is 
Saudi Arabia : 1999
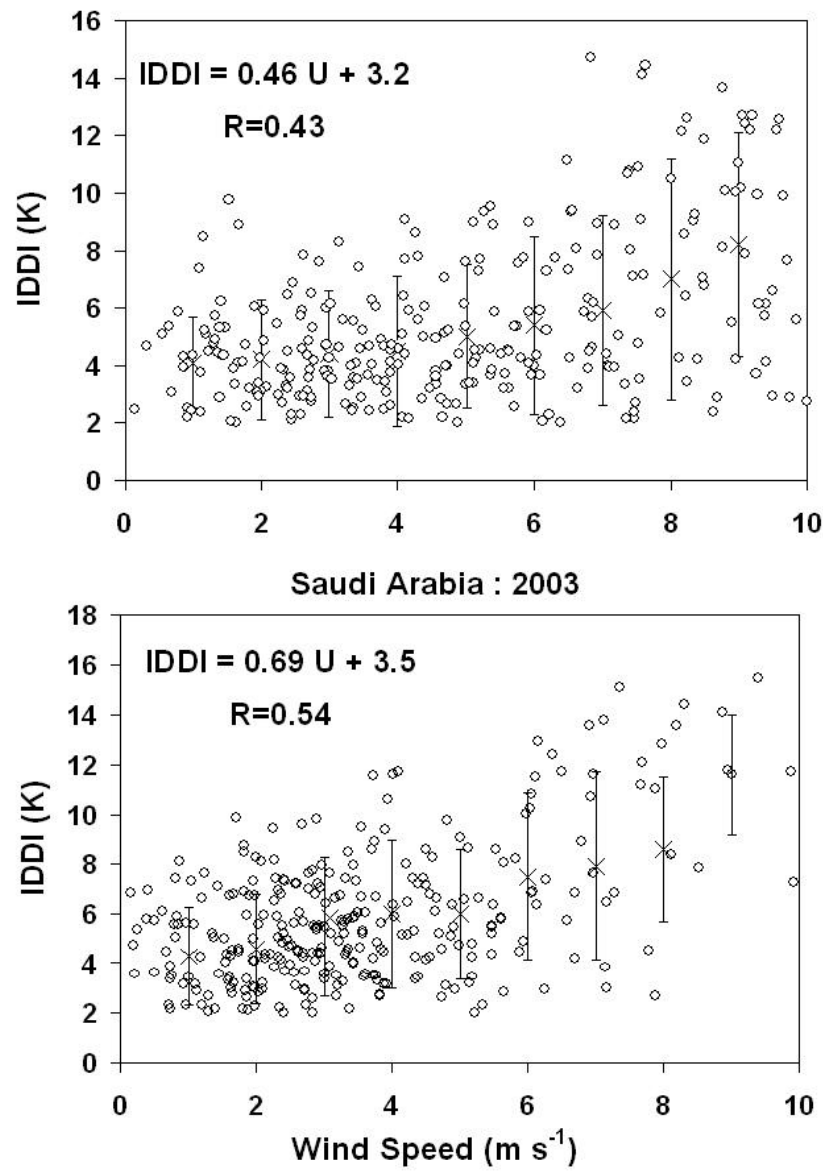

Fig. 7. Scatter plot of daily IDDI versus wind speed for Saudi Arabia. The solid line represents linear least-squares fit to the data points.

balanced by the radiative heating of dust aerosols at low levels. The dust aerosols over the Arabian Sea warm the levels between 800 and $600 \mathrm{hPa}(\sim 0.2 \mathrm{~K}$ per day $)$ and cool the lower levels during the daytime (Alpert et al., 1998; Mohalfi et al., 1998). Thus, the presence of dust transported over oceans intensifies a low-level inversion, which, in turn, affects the stability of the atmosphere (Miller and Tegen, 1999; Mohalfi et al., 1998).

The monthly mean IDDI values were estimated for all seven representative regions defined in Part I (Saudi ArabiaI, $19^{\circ} \mathrm{N}-24^{\circ} \mathrm{N}$ and $53^{\circ} \mathrm{E}-58^{\circ} \mathrm{E}$; Saudi Arabia-II, $19^{\circ} \mathrm{N}-$ $24^{\circ} \mathrm{N}$ and $45^{\circ} \mathrm{E}-50^{\circ} \mathrm{E}$; NE Africa, $5^{\circ}-10^{\circ} \mathrm{N}, 35^{\circ} \mathrm{E}-40^{\circ} \mathrm{E}$; Somalia, $5^{\circ}-10^{\circ} \mathrm{N}$ and $43^{\circ} \mathrm{E}-48^{\circ} \mathrm{E}$; Indian Desert (Rajasthan), $25^{\circ} \mathrm{N}-30^{\circ} \mathrm{N}, 70^{\circ} \mathrm{E}-76^{\circ} \mathrm{E}$; Gujarat, $21^{\circ} \mathrm{N}-25^{\circ} \mathrm{N}$, $68^{\circ} \mathrm{E}-76^{\circ} \mathrm{E}$; Central India, $\left.25^{\circ} \mathrm{N}-30^{\circ} \mathrm{N}, 75^{\circ} \mathrm{N}-85^{\circ} \mathrm{E}\right)$. The monthly mean IDDI was in the range of 3 to 9 (Tables 3 and 4). The regional average of the entire region considered in this study $\left(0-35^{\circ} \mathrm{N} ; 30^{\circ} \mathrm{E}-100^{\circ} \mathrm{E}\right)$ (annually averaged over land only) was $5.7 \pm 1.2$. By its omnipresence, the desert aerosol can cause a significant impact on the atmospheric radiation. Mineral dust aerosols constitute a major fraction of
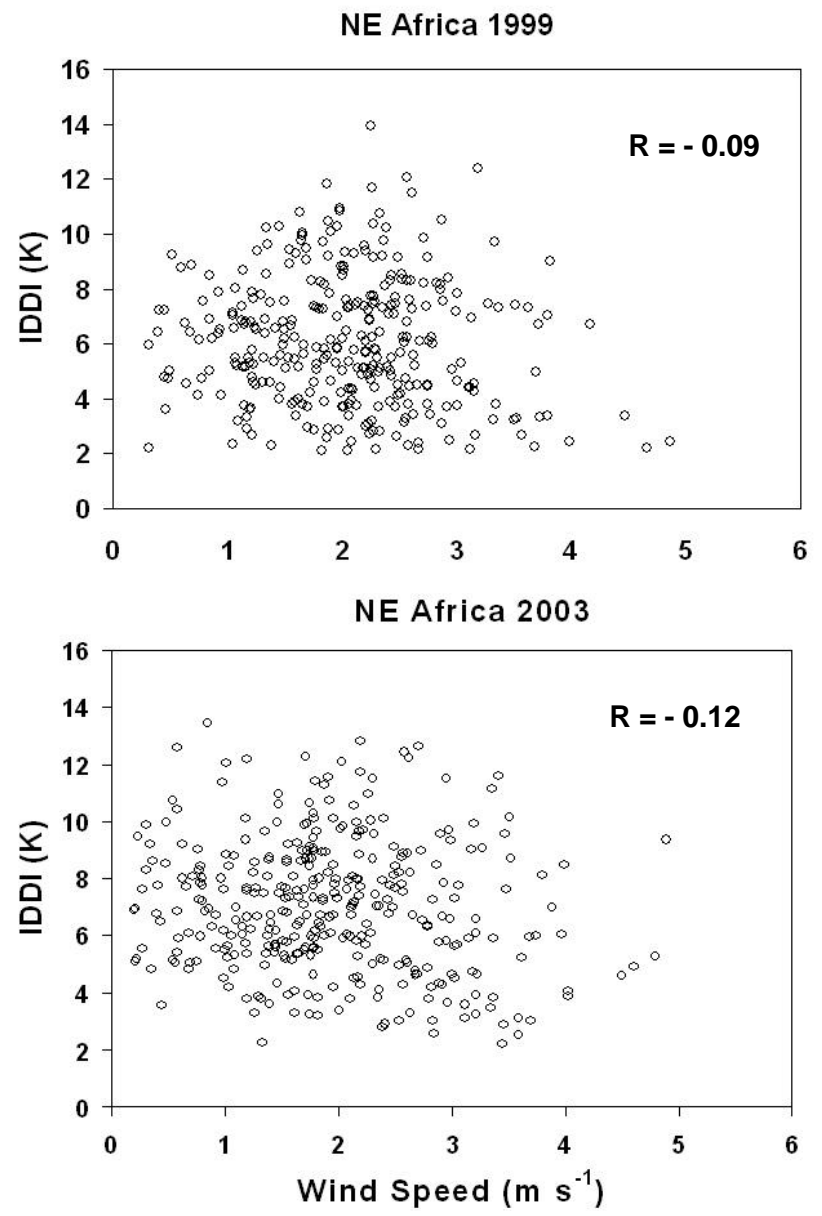

Fig. 8. Scatter plot of daily IDDI versus wind speed for NE Africa. The solid line represents linear least-squares fit to the data points.

global aerosol abundance and have an important role in regulating global climate (Prospero et al., 2002; Christopher et al., 2003; Tanré et al., 2003). However, the optical and radiative properties of dust (on a large spatial scale) are not known precisely, due to a lack of an adequate database (Seinfeld et al., 2004). The radiative effects of dust depend strongly on Single Scattering Albedo (SSA), which, in turn, depends on the complex refractive index. The SSA of dust reported by various studies, however, shows discrepancies (Deepshikha et al., 2005). Recent studies have shown that the refractive indices used for dust aerosols in global models are not accurate. For example, Kaufman et al. (2001), using remote sensing, inferred the SSA of the Saharan dust as 0.97 at $0.55 \mu \mathrm{m}$. The studies on the Saharan dust by Haywood et al. (2003) have shown that the SSA of dust at $0.55 \mu \mathrm{m}$ is in the range of 0.95 to 0.99 . Here, we have used dust optical properties reported by Hess et al. (1998) and Kaufman et al. (2001) and incorporated them in a Discrete Ordinate Radiative Transfer (RT) model developed by the University of Santa Barbara (SBDART) (Ricchiazzi et al., 1998), to estimate the aerosol impact (forcing) on the short-wave (SW) fluxes (see Satheesh et al., 1999 for details). Using these data 
on dust optical properties we have modeled IDDI as a function of dust optical depth. Here, IDDI was estimated (using SBDART) for each optical depth value. An example of change in IRBT as a function of dust optical depth, estimated using dust properties reported by Hess et al. (1998), is shown in Fig. 12. We have then used the relation between IDDI and optical depth (Fig. 12) to estimate dust optical depth from IDDI. The visible optical depth was about three times larger compared to the optical depth at $11 \mu \mathrm{m}$. The surface temperature is obtained from IRBT as a reference temperature. Two cases are considered here and are represented as Forcing-1 (correspond to SSA 0.82; based on Hess et al., 1998) and Forcing-2 (correspond to SSA $\sim 0.97$; based on Kaufman et al., 2001). The surface reflection in all these cases were obtained from MODIS Albedo Product (MODIS/Terra Albedo; 16-Day; Level-3 Global 1-km Grid). The monthly mean IDDI values estimated for the four regions are shown in Fig. 13 and for all regions in Tables 3 and 4. The dust optical depth and optical properties were incorporated in the radiative transfer model (SBDART) and estimated SW radiative forcing. The SW dust forcing at the top of the atmosphere thus estimated for the four locations is also shown in Fig. 13 and for all regions in Table 5. The regionally and annually averaged SW dust forcing (clear-sky) at the top of the atmosphere over the entire study region $\left(0-35^{\circ} \mathrm{N} ; 30^{\circ} \mathrm{E}-\right.$ $100^{\circ} \mathrm{E}$ ) was in the range from -0.9 to $+4.5 \mathrm{~W} \mathrm{~m}^{-2}$ (Table 5), and surface radiative forcing was in the range from -10 to $25 \mathrm{~W} \mathrm{~m}^{-2}$ (Table 6). The values shown in Table 6 show that single scattering albedo has a significant role in determining the forcing. Over regions such as central India, where dust and anthropogenic aerosols are plenty, the possibility of an internal mixture is quite high. Chandra et al. (2004) have shown that when black carbon aerosols accumulate over dust, the composite aerosol absorption further increases (SSA decreases).

2.3 Nighttime retrieval of dust aerosols: implications on LW radiative forcing

It is typical to use visible wavelengths to retrieve aerosols, using remote sensing (Kaufman et al., 1997). Remote sensing over deserts using visible wavelengths is complicated due to the high and varying surface reflection properties of land. Recently, Hsu et al. (2004) has demonstrated that aerosol optical depths can be derived using MODIS data over bright surfaces. Martonchik et al. (2004) has compared MISR derived optical depths with those measured by AERONET sites over deserts and found agreement. Visible wavelengths, however, provide data only during the daytime. There are instances when it is essential to monitor dust loading continuously. Hence, IR remote sensing provides an excellent opportunity for continuous dust aerosol retrieval. The METEOSAT provides infrared radiance data every half an hour, covering day and night. A typical set of three hourly reference images is shown in Fig. 14. The time marked in Fig. 14 is Indian Standard Time (IST). The diurnal variation of IRBT is clearly visible in Fig. 14. Over the Arabian deserts, IRBT changes
Rajasthan 1999
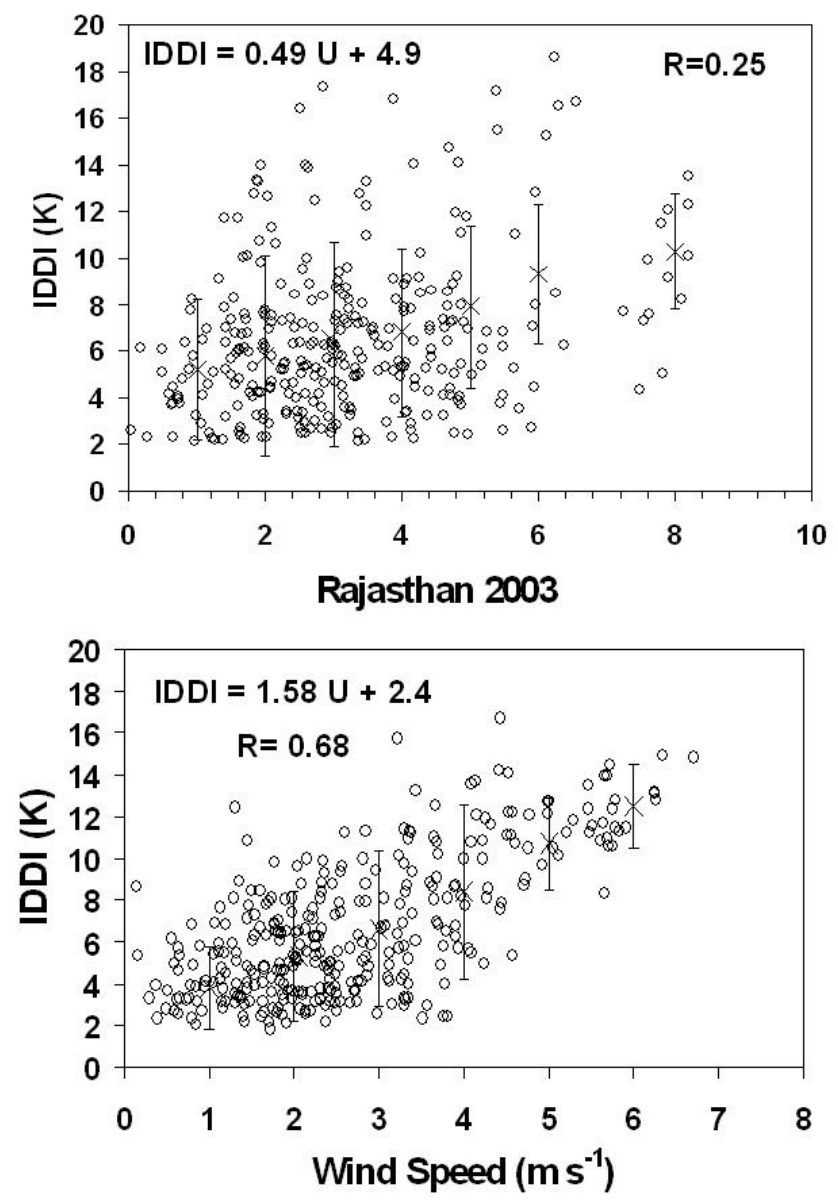

Fig. 9. Scatter plot of daily IDDI versus wind speed for Rajasthan. The solid line represents linear least-squares fit to the data points.

from $295 \mathrm{~K}$ (early morning) to $325 \mathrm{~K}$ (noon) in a day. Thus, for a given dust load, its radiative impact changes as IRBT changes with time. To study this effect, sensitivity studies have been carried out. We considered the desert model of Hess et al. (1998) for this purpose. Using model simulations, we show in Fig. 15 the effect of surface temperature on dustinduced reduction in IRBT. It can be seen that for the same dust optical depth, as surface temperature changes, reduction in IRBT also changes. This implies that the quantitative assessment of dust load inferred from infrared data needs to be corrected for the surface temperature effect. Note that this correction is required to convert nighttime IDDI to "equivalent noontime" IDDI. However, for estimation of LW radiative forcing this correction is not needed.

When extending the IDDI method to the daily cycle, we have pointed out the fact that the large diurnal surface temperature amplitude involves a change in the IRBT depletion at the TOA for a fixed dust amount (Fig. 15). In fact, things are somewhat more complex. The dust radiative impact involves temperature changes, mainly at the surface, resulting, in turn, in variations of the IRBT at the TOA and of the IDDI. 
Table 2. Regression parameters of wind dependence.

\begin{tabular}{|l|l|l|l|l|l|l|}
\hline \multirow{2}{*}{ Location } & \multicolumn{2}{|c|}{ Slope / Exponent } & \multicolumn{2}{c|}{ Intercept } & \multicolumn{2}{l|}{ Correlation Coefficient } \\
\cline { 2 - 7 } & 1999 & 2003 & 1999 & 2003 & 1999 & 2003 \\
\hline SA-1 & $0.46(0.11)$ & $0.69(0.15)$ & 3.2 & 3.5 & 0.43 & 0.54 \\
\hline SA-2 & $0.53(0.12)$ & $0.63(0.14)$ & 3.0 & 3.9 & 0.46 & 0.62 \\
\hline Rajasthan & $0.49(0.12)$ & $1.58(0.24)$ & 4.9 & 2.4 & 0.25 & 0.68 \\
\hline Somalia & $0.31(0.09)$ & $0.39(0.10)$ & 3.8 & 3.5 & 0.31 & 0.38 \\
\hline NE Africa & --- & --- & --- & --- & -0.09 & -0.12 \\
\hline
\end{tabular}

\section{Diff. Surface Soil Moisture (fraction)}
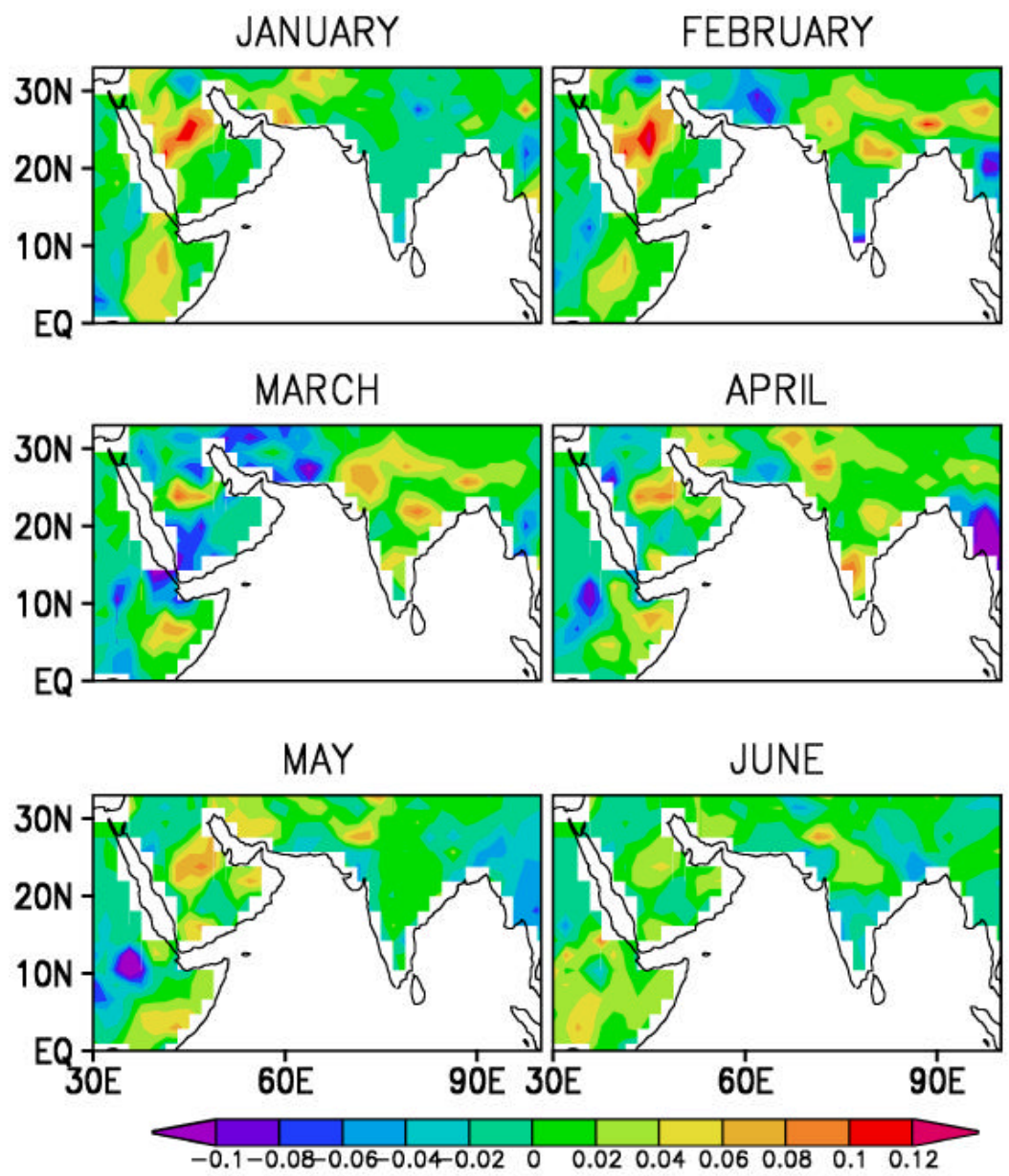

Fig. 10. The difference in soil moisture between 2003 and 1999 (January to June).

At noon, the main effect is the surface cooling due to the large fraction of solar radiation backscattered to space (it can be typically $5 \mathrm{~K}$ for a unit optical depth). But during the night the surface effect is a heating due to the "greenhouse effect" of dust (similar to the effect of a nocturnal cloud cover weakening the surface cooling to space). If dust is in the boundary layer, this surface effect is the main one and dust is viewed from space as a hot patch: in such a case the so-called IDDI would be negative. This nocturnal behavior of dust has been confirmed with observations (Legrand et al., 1989) and analysed with simulations (Legrand et al. 1992). When dust layers are low, the above situation generally holds true. On the other hand, for elevated dust layers, this surface heating will vanish and the space observation of dust will turn to be an IRBT depletion, because the dust layer is then colder than the surface. But even in such cases, the daylight cooling is zero. 


\section{Diff. Surface Soil Moisture (fraction)}
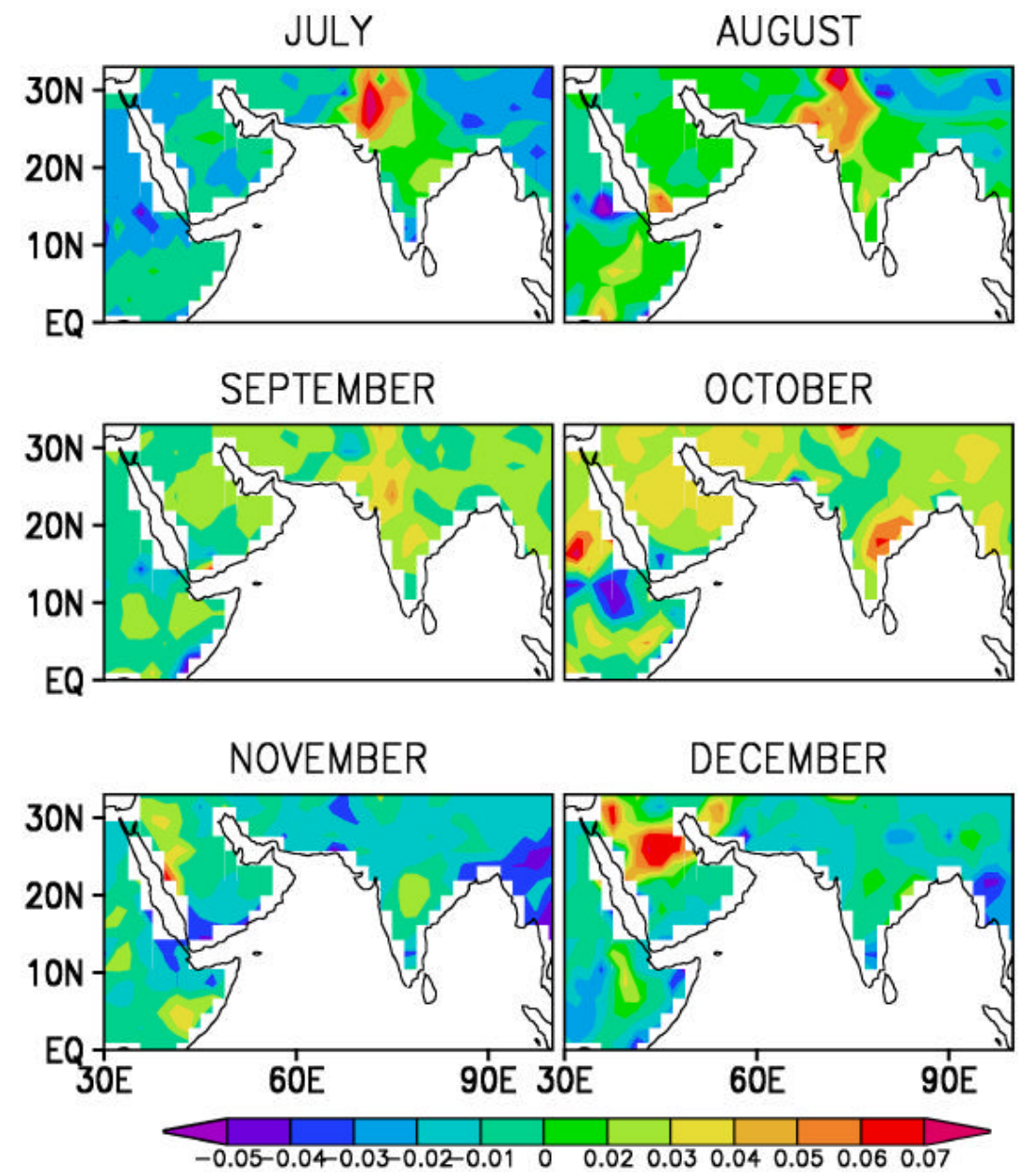

Fig. 11. The difference in soil moisture between 2003 and 1999 (July to December).

Table 3. Comparison of monthly mean IDDI (K).

\begin{tabular}{|l|c|c|c|c|c|c|}
\hline \multirow{2}{*}{ Month } & \multicolumn{2}{|c|}{ Saudi Arabia-I } & \multicolumn{2}{c|}{ Saudi Arabia-II } & \multicolumn{2}{c|}{ Rajasthan } \\
\cline { 2 - 7 } & 1999 & 2003 & 1999 & 2003 & 1999 & 2003 \\
\hline Jan & $4.0 \pm 1.9$ & $4.4 \pm 2.3$ & $4.3 \pm 1.7$ & $6.0 \pm 2.1$ & $6.1 \pm 1.9$ & $5.3 \pm 2.2$ \\
\hline Feb & $4.6 \pm 1.9$ & $5.6 \pm 3.4$ & $5.5 \pm 1.6$ & $6.7 \pm 1.8$ & $6.2 \pm 2.5$ & $6.5 \pm 3.8$ \\
\hline Mar & $5.5 \pm 2.1$ & $6.7 \pm 3.6$ & $6.6 \pm 1.9$ & $8.2 \pm 2.7$ & $6.4 \pm 3.2$ & $5.7 \pm 2.5$ \\
\hline Apr & $4.9 \pm 1.9$ & $7.3 \pm 3.9$ & $5.5 \pm 2.0$ & $7.8 \pm 2.4$ & $4.1 \pm 1.6$ & $6.5 \pm 3.2$ \\
\hline May & $5.0 \pm 3.0$ & $6.3 \pm 2.8$ & $6.1 \pm 2.2$ & $6.6 \pm 2.5$ & $8.7 \pm 3.8$ & $7.4 \pm 3.5$ \\
\hline Jun & $4.5 \pm 1.6$ & $5.6 \pm 2.6$ & $4.3 \pm 1.7$ & $5.2 \pm 1.9$ & $7.3 \pm 3.4$ & $8.5 \pm 3.1$ \\
\hline Jul & $5.3 \pm 1.9$ & $6.9 \pm 2.6$ & $4.5 \pm 1.6$ & $5.8 \pm 1.8$ & $8.6 \pm 4.4$ & $9.3 \pm 3.5$ \\
\hline Aug & $4.1 \pm 0.9$ & $6.3 \pm 3.7$ & $3.9 \pm 1.3$ & $6.3 \pm 2.6$ & $6.4 \pm 3.9$ & $7.3 \pm 2.7$ \\
\hline Sep & $5.1 \pm 0.7$ & $5.3 \pm 1.5$ & $3.8 \pm 1.4$ & $5.6 \pm 1.6$ & $5.7 \pm 2.3$ & $7.0 \pm 2.8$ \\
\hline Oct & $5.0 \pm 1.0$ & $5.8 \pm 2.6$ & $3.5 \pm 1.1$ & $5.7 \pm 1.8$ & $4.4 \pm 2.5$ & $3.8 \pm 2.1$ \\
\hline Nov & $3.7 \pm 1.5$ & $4.3 \pm 1.9$ & $3.7 \pm 1.2$ & $4.5 \pm 1.6$ & $3.5 \pm 1.8$ & $4.2 \pm 2.3$ \\
\hline Dec & $2.5 \pm 0.6$ & $4.7 \pm 2.5$ & $2.7 \pm 0.8$ & $4.6 \pm 1.8$ & $3.8 \pm 1.9$ & $3.7 \pm 2.6$ \\
\hline $\begin{array}{l}\text { Annual } \\
\text { Average }\end{array}$ & $4.5 \pm 0.84$ & $5.8 \pm 1.0$ & $4.6 \pm 1.0$ & $6.1 \pm 1.1$ & $5.9 \pm 1.7$ & $6.3 \pm 1.8$ \\
\hline
\end{tabular}




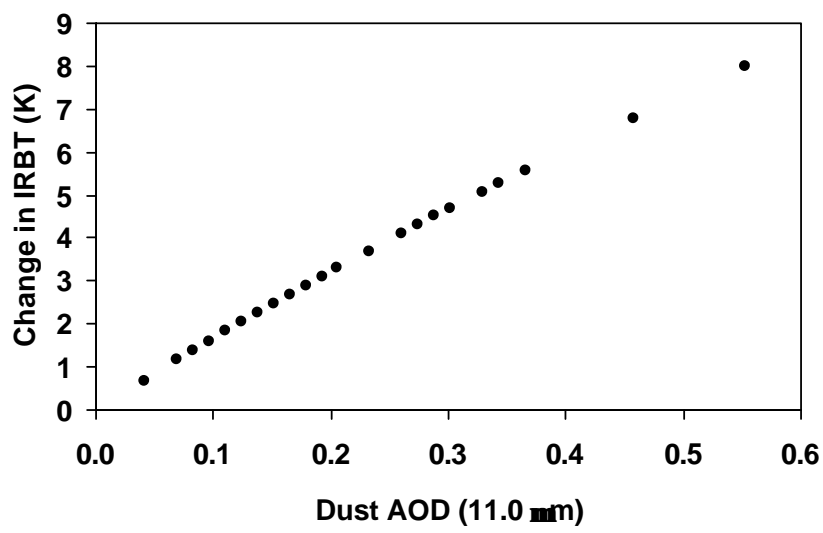

Fig. 12. Change in IRBT as a function of dust optical depth at $11 \mu \mathrm{m}$. Here, dust aerosol model of Hess et al. (1998) was used.

The apparent issue in these circumstances is that the IDDI algorithm, valid for daytime, will no longer hold during the night (because dust is then hotter than the theoretical dustfree reference, while clouds are colder). The daytime IDDI algorithm will eliminate clouds and keep with the most dust cases. A possible solution is to re-order the steps of daytime algorithm. We have made an attempt based on the following steps.

1. Follow the daytime IDDI algorithm: Create "reference image" representing the hottest pixels.

2. Create "difference image" and then use it for cloud identification and masking.

3. Apply the cloud mask to the original IRBT images.

4. Apply the IDDI algorithm again, but with the "minimum reference".

An example of nighttime IDDI images constructed following the above procedure is shown in Fig. 16. It may be noted that while using the "minimum" reference method for retrieval of IDDI during the night, IDDI is negative. In Fig. 16 we show the absolute value of IDDI. These images correspond to the images shown in Fig. 16 of Part I. The dust cloud observed during the noontime images (Fig. 16 of Part I) is also observed in the nighttime images. A typical example of diurnal variation of IRBT and IDDI (for 5 May 1999) is shown in Fig. 17 at two locations, Rajasthan (marked as Raj. in the figure) in Northwest India and Saudi Arabia-I (marked as SA in the figure). The diurnal (3-hourly) variation of IDDI observed during May 1999 is shown in Fig. 18. Figures 17 and 18 indicate that there is a significant diurnal variation in the dust. A detailed analysis in this regard suggests that the maximum dust load occurs during the daytime. The maximum change in IDDI is as much as a factor of three between daytime and nighttime, and factor of two variations are commonly observed. This observation has a consequent impact on its long-wave radiative forcing. During daytime, when
Table 4. Comparison of monthly mean IDDI (K).

\begin{tabular}{|l|c|l|l|l|}
\hline \multirow{2}{*}{ Month } & \multicolumn{2}{|c|}{ NE Africa } & \multicolumn{2}{c|}{ Somalia } \\
\cline { 2 - 5 } & 1999 & 2003 & 1999 & 2003 \\
\hline Jan & $4.9 \pm 2.9$ & $6.1 \pm 2.8$ & $4.4 \pm 2.5$ & $5.9 \pm 2.6$ \\
\hline Feb & $4.2 \pm 1.7$ & $6.0 \pm 2.2$ & $5.2 \pm 1.8$ & $5.6 \pm 2.3$ \\
\hline Mar & $6.7 \pm 2.0$ & $7.2 \pm 2.1$ & $6.4 \pm 1.6$ & $6.9 \pm 2.0$ \\
\hline Apr & $7.0 \pm 2.6$ & $8.5 \pm 2.4$ & $6.8 \pm 2.2$ & $7.8 \pm 2.1$ \\
\hline May & $6.4 \pm 2.3$ & $6.8 \pm 2.1$ & $6.2 \pm 2.5$ & $7.2 \pm 1.9$ \\
\hline Jun & $6.1 \pm 2.3$ & $7.5 \pm 2.0$ & $6.4 \pm 2.6$ & $8.1 \pm 2.2$ \\
\hline Jul & $8.0 \pm 1.9$ & $7.6 \pm 1.7$ & $8.3 \pm 2.4$ & $9.0 \pm 2.7$ \\
\hline Aug & $6.6 \pm 1.9$ & $8.0 \pm 2.5$ & $7.1 \pm 2.1$ & $7.3 \pm 2.6$ \\
\hline Sep & $5.8 \pm 1.7$ & $6.5 \pm 1.4$ & $6.0 \pm 1.8$ & $6.7 \pm 2.1$ \\
\hline Oct & $7.3 \pm 2.6$ & $6.1 \pm 1.7$ & $6.3 \pm 2.1$ & $6.4 \pm 1.9$ \\
\hline Nov & $4.8 \pm 1.6$ & $6.3 \pm 2.6$ & $5.8 \pm 1.4$ & $6.5 \pm 2.5$ \\
\hline Dec & $3.1 \pm 1.1$ & $6.4 \pm 3.3$ & $3.4 \pm 1.3$ & $6.8 \pm 2.4$ \\
\hline Annual & $5.9 \pm 1.4$ & $6.9 \pm 0.8$ & $6.0 \pm 1.3$ & $7.0 \pm 1.0$ \\
Average & & & & \\
\hline
\end{tabular}

surface temperature is maximum, the dust load is also maximum while at night surface temperature decreases,as well as the dust load. To demonstrate this fact, we show in Fig. 19 the effect of surface temperature on OLR and long-wave radiative forcing. Case- 1 and Case- 2 represent two different cases of dust loading, which differ by a factor of three. Case1 corresponds to a desert aerosol with a visible optical depth of 1.0. Sensitivity studies carried out in this regard have indicated that neglecting the diurnal variation in dust loading results in errors in the estimate of long-wave radiative by forcing as much as 50 to $100 \%$. During the dry season over source regions long-wave radiative forcing was as high as +10 to $+15 \mathrm{~W} \mathrm{~m}^{-2}$. The regionally $\left(0-35^{\circ} \mathrm{N} ; 30^{\circ} \mathrm{E}-100^{\circ} \mathrm{E}\right)$ and annually averaged long-wave dust radiative forcing was $+3.4 \pm 1.6 \mathrm{~W} \mathrm{~m}^{-2}$.

Liao and Seinfeld (1998) examined global mean radiative forcing by mineral dust aerosols in short-wave and longwave regions, using a 1-D column radiation model. They estimated clear-sky, short-wave radiative forcing at TOA as $-2 \mathrm{~W} \mathrm{~m}^{-2}$ at low surface reflection $(\sim 0.1)$, and $+2 \mathrm{~W} \mathrm{~m}^{-2}$ at high surface reflection $(\sim 0.5)$. They also observed that unlike scattering aerosols, such as sea salt, dust radiative forcing depends on the surface reflection and the altitude at which the dust layer is located. Clear-sky, long-wave radiative forcing at TOA was in the range of +0.2 to $+1.0 \mathrm{~W} \mathrm{~m}^{-2}$. These results are consistent with Tegen and Lacis (1996) and Tegen et al. (1997).

\section{Conclusions}

- The frequency of dust events was higher during 2003 compared to 1999. 

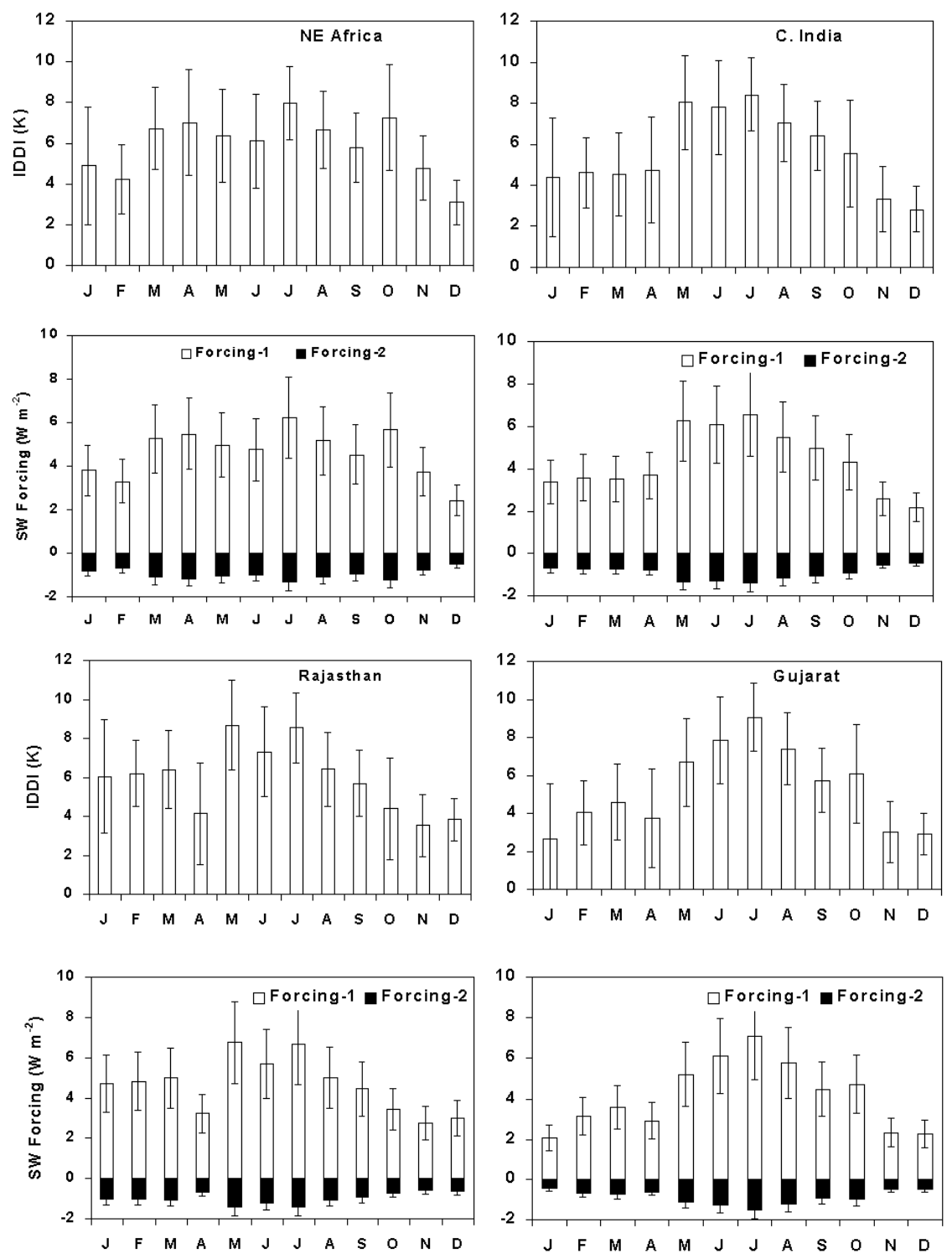

Fig. 13. Monthly mean IDDI and SW dust radiative forcing at four representative regions estimated using two different dust optical properties reported earlier.

Table 5. SW dust radiative forcing at top of the atmosphere for 1999.

\begin{tabular}{|c|c|c|c|c|c|c|c|c|c|}
\hline \multirow[t]{3}{*}{ Location } & \multicolumn{3}{|c|}{ IDDI (K) } & \multicolumn{6}{|c|}{ SW Dust Radiative Forcing $\left(\mathrm{W} \mathrm{m}^{-2}\right)$} \\
\hline & \multirow[t]{2}{*}{ July } & \multirow[t]{2}{*}{ Dec. } & \multirow{2}{*}{$\begin{array}{l}\text { Ann. } \\
\text { Mean }\end{array}$} & \multicolumn{2}{|l|}{ July } & \multicolumn{2}{|l|}{ Dec. } & \multicolumn{2}{|c|}{ Ann. Mean } \\
\hline & & & & F-1 & F-2 & F-1 & F-2 & F-1 & $\mathrm{F}-2$ \\
\hline Saudi Arabia-I & 5.3 & 2.5 & 4.5 & +4.1 & -0.8 & +2.0 & -0.3 & +3.6 & -0.6 \\
\hline Saudi Arabia-II & 4.3 & 2.7 & 4.6 & +3.3 & -0.6 & +2.1 & -0.4 & +3.7 & -0.6 \\
\hline NE Africa & 8.0 & 3.1 & 5.9 & +6.2 & -1.3 & +2.4 & -0.5 & +4.6 & -1.0 \\
\hline Somalia & 8.3 & 3.4 & 6.9 & +6.4 & -1.4 & +2.7 & -0.5 & +5.1 & -1.3 \\
\hline C. India & 8.4 & 2.8 & 5.6 & +6.6 & -1.4 & +2.2 & -0.5 & +4.4 & -0.9 \\
\hline Rajasthan & 8.6 & 3.8 & 5.9 & +6.7 & -1.5 & +3.0 & -0.6 & +4.6 & -1.0 \\
\hline Gujarat & 9.1 & 2.9 & 5.3 & +7.0 & -1.6 & +2.3 & -0.5 & +4.1 & -0.9 \\
\hline $\begin{array}{l}\text { Regional } \\
\text { Average** }\end{array}$ & 7.7 & 3.0 & 5.7 & +6.0 & -1.3 & +2.3 & -0.5 & +4.5 & -0.9 \\
\hline
\end{tabular}




\section{Hrly Reference Images May (1-15) 1999}
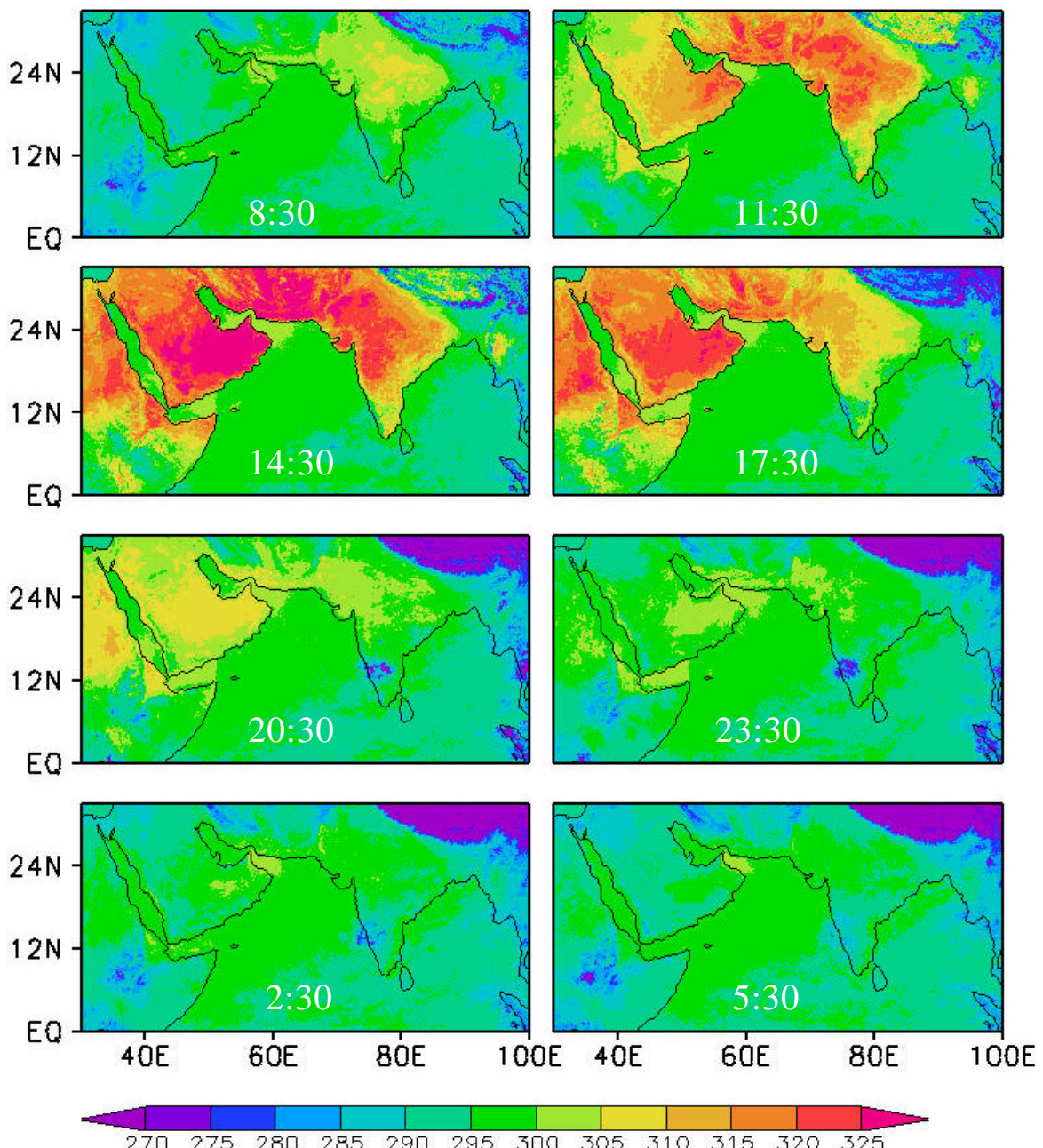

Fig. 14. A typical set of three-hourly reference images (in K). The time marked in figure is Indian Standard Time (IST).

Table 6. SW dust radiative forcing at the surface for 1999.

\begin{tabular}{|l|l|l|l|l|l|l|}
\hline \multirow{2}{*}{ Location } & \multicolumn{5}{|c|}{ SW Dust Surface Radiative Forcing $\left(\mathrm{W} \mathrm{m}^{-2}\right)$} \\
\cline { 2 - 7 } & July & \multicolumn{1}{l|}{ Dec. } & \multicolumn{3}{l|}{ Ann. Mean } \\
\cline { 2 - 7 } & F-1 & F-2 & F-1 & F-2 & F-1 & F-2 \\
\hline Saudi Arabia-I & -21.4 & -12.9 & -11.0 & -6.6 & -18.4 & -11.1 \\
\hline Saudi Arabia-II & -18.2 & -10.7 & -12.8 & -6.5 & -17.4 & -10.4 \\
\hline NE Africa & -31.0 & -16.0 & -11.4 & -7.2 & -22.6 & -12.3 \\
\hline Somalia & -34.2 & -17.7 & -12.6 & -7.7 & -24.6 & -16.5 \\
\hline C. India & -32.6 & -18.9 & -11.2 & -6.3 & -24.4 & -11.6 \\
\hline Rajasthan & -35.4 & -19.4 & -15.2 & -8.6 & -22.6 & -14.3 \\
\hline Gujarat & -37.4 & -20.5 & -11.6 & -6.5 & -21.2 & -12.9 \\
\hline $\begin{array}{l}\text { Regional } \\
\text { Average* }\end{array}$ & -32.8 & -17.3 & -12.0 & -6.8 & -22.8 & -11.8 \\
\hline
\end{tabular}

* Over the region covered by $0-35^{\circ} \mathrm{N} ; 30^{\circ} \mathrm{E}-100^{\circ} \mathrm{E}$; land only
- The increase in IDDI with wind speed was nearly linear and the rate of increase was higher during 2003 compared to 1999 over all the dry regions considered.

- Over the Indian deserts, when the wind speed was the highest during the monsoon months (June to August), the dust production rate was lower because of higher soil moisture (due to monsoon rainfall).

- Over the deserts of Saudi Arabia, when the wind speed was the highest during June to August, the dust production rate was also the highest, as soil moisture was the lowest during this season.

- It appears that the deserts in Northwest India are more efficient dust sources compared to Saudi Arabia and Africa (excluding Sahara).

- The radiative impact of dust over various source regions is estimated, and the regionally and annually averaged 


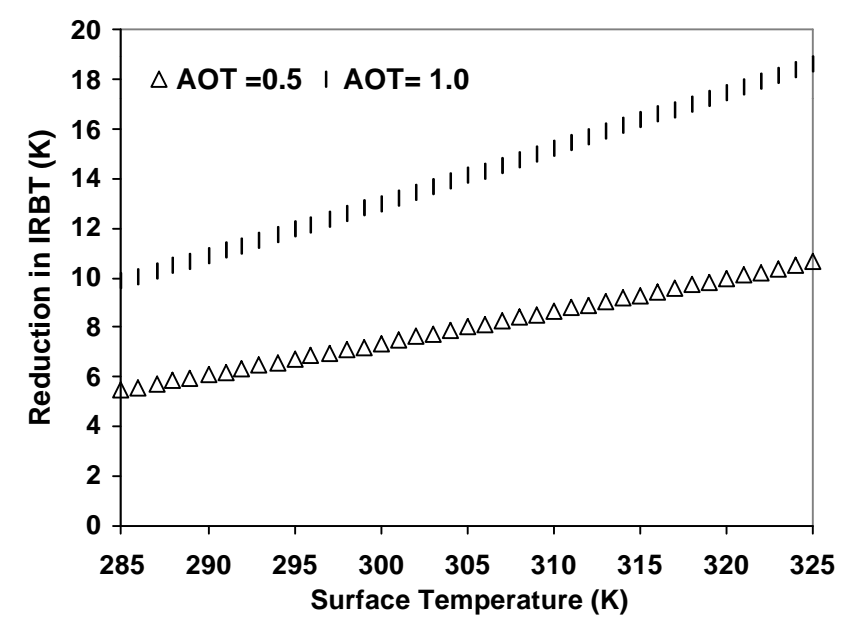

Fig. 15. The effect of surface temperature on reduction of IRBT (i.e. IDDI) estimated for two different optical depths. Here, desert aerosol model of Hess et al. (1998) was used. The IDDI is in K.

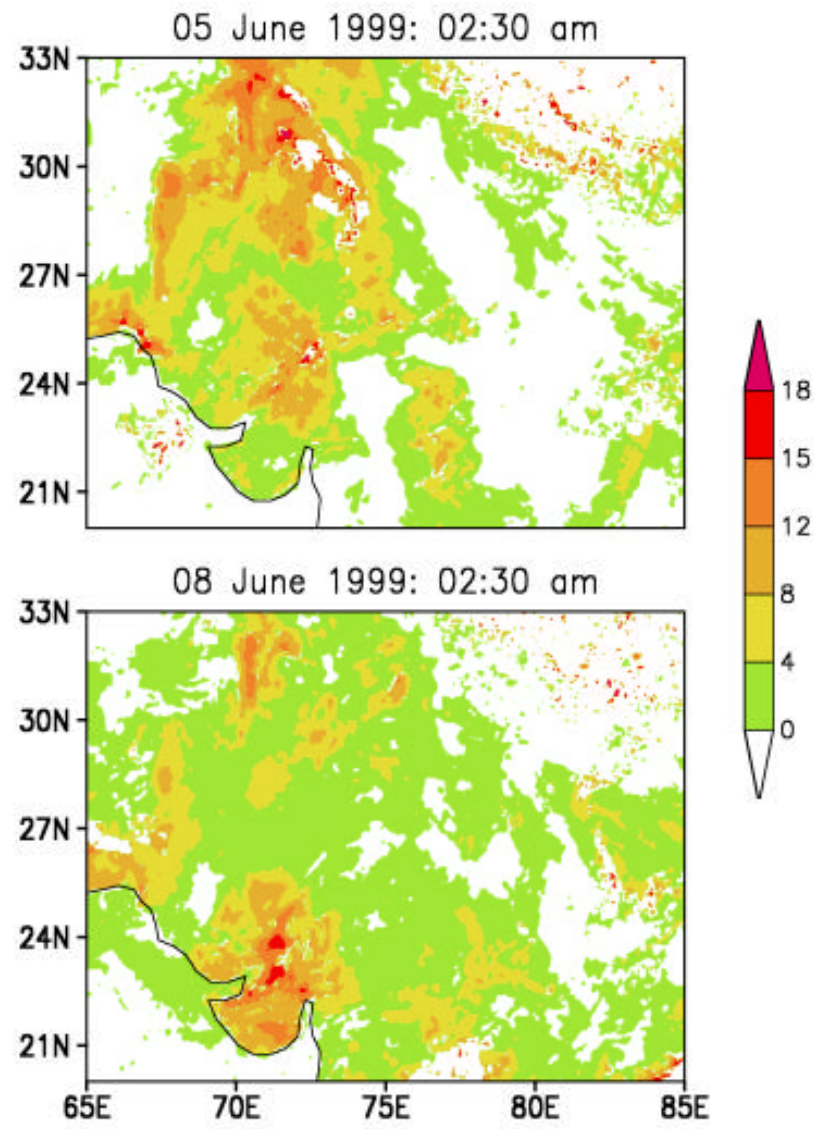

Fig. 16. Nighttime image of dust event. The IDDI is in K.
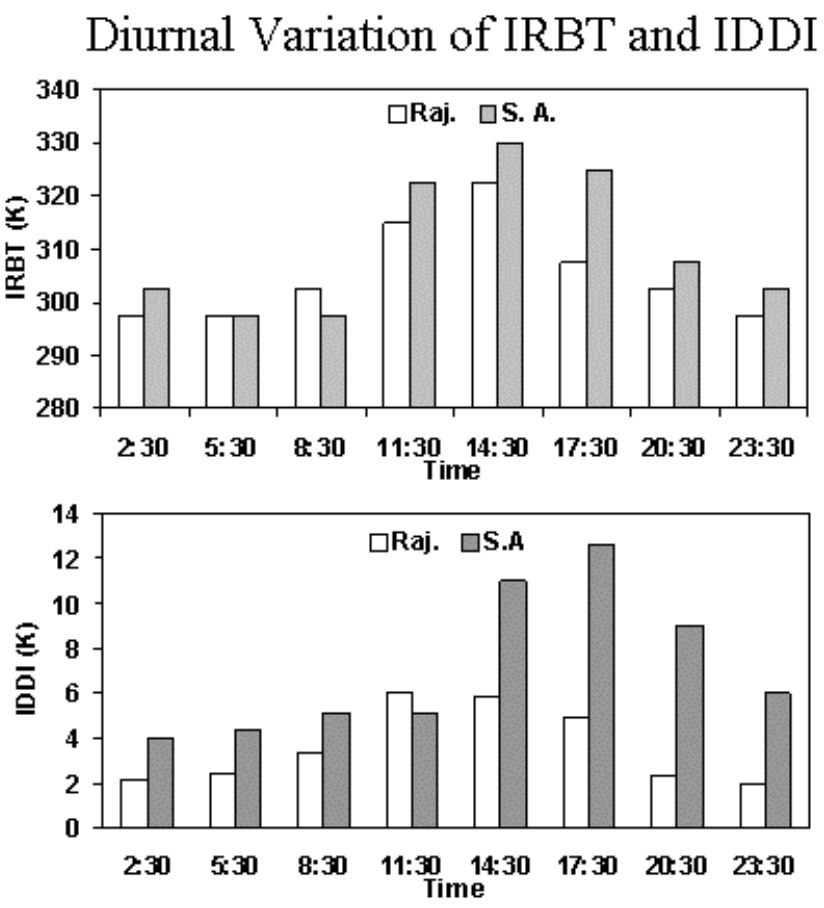

Fig. 17. A typical example of diurnal variation of IRBT $(\mathrm{K})$ and IDDI (K) at two representative regions; Rajasthan (Raj. in plot) and Saudi Arabia (SA in plot) (for 5 May 1999).
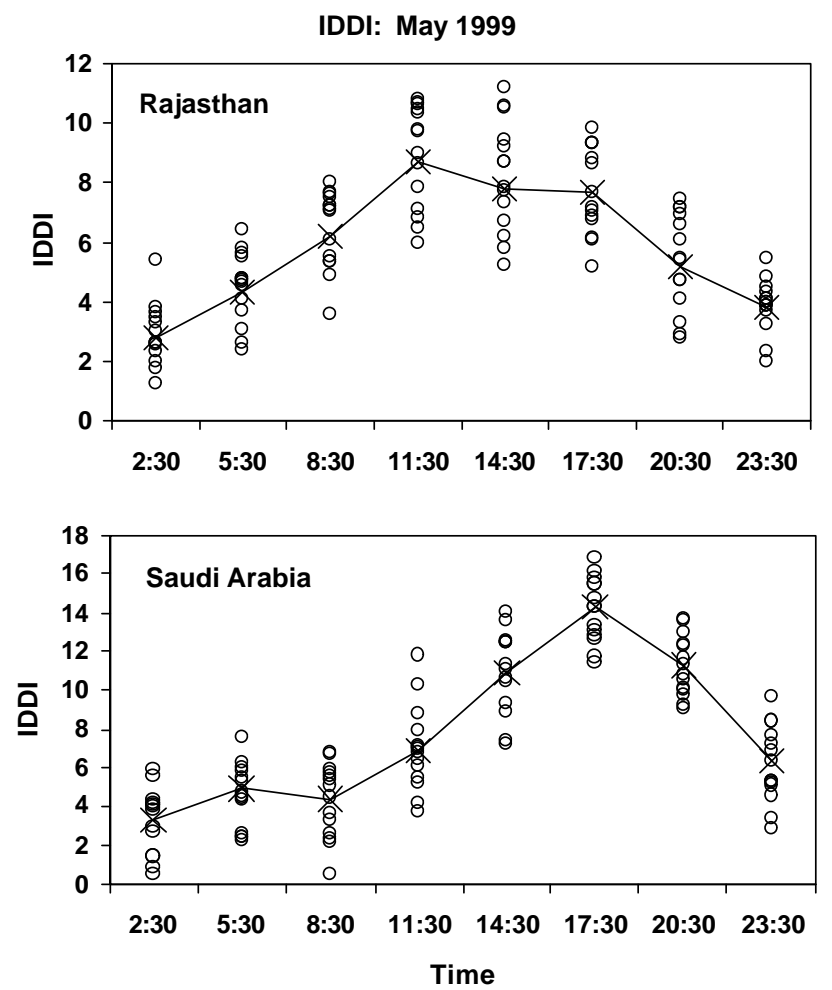

Fig. 18. Diurnal variation of IDDI (K) for May 1999. 

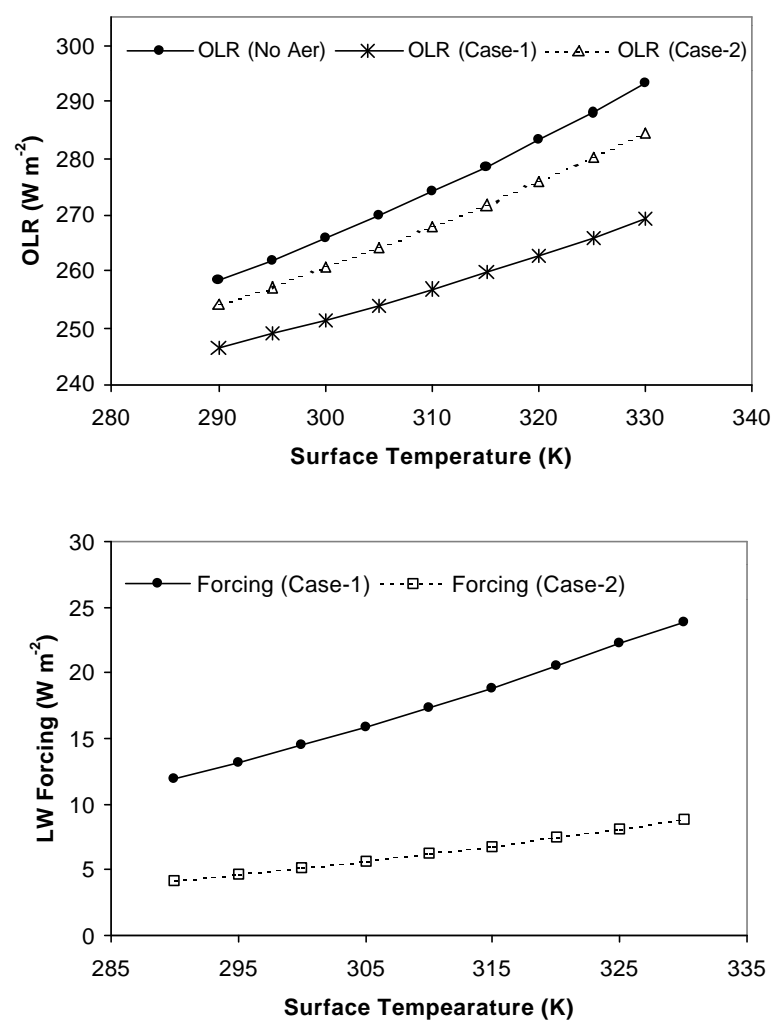

Fig. 19. (a) Effect of surface temperature on OLR (b) Effect of surface temperature on long wave radiative forcing. Here, case- 1 and case- 2 correspond to aerosol optical depths 1.0 and 0.33 , respectively. Desert aerosol model of Hess et al. (1998) was used.

dust radiative forcing (short-wave, clear-sky and over land) was in the range of -0.9 to $+4.5 \mathrm{~W} \mathrm{~m}^{-2}$. The corresponding values at the surface were in the range of 10 to $25 \mathrm{~W} \mathrm{~m}^{-2}$.

- A method to retrieve dust aerosols during nighttime has been proposed.

- Our studies demonstrate that neglecting the diurnal variation of dust causes errors in the estimate of long-wave dust forcing by as much as 50 to $100 \%$, and nighttime retrieval of dust can significantly reduce the uncertainties.

- The long-wave dust radiative forcing was as high as +10 to $+15 \mathrm{~W} \mathrm{~m}^{-2}$, with a regionally and annually averaged value of $+3.4 \pm 1.6 \mathrm{~W} \mathrm{~m}^{-2}$.

Acknowledgements. The authors thank Department of Science and Technology, New Delhi for supporting this work. We also thank LMD and EUMETSAT for providing METEOSAT-5 data and NCEP/NCAR for providing wind and soil moisture data. We sincerely thank the anonymous referees for their valuable suggestions, which has improved the quality of the paper substantially.

Topical Editor O. Boucher thanks three referees for their help in evaluating this paper.

\section{References}

Alpert, P., Kaufman, Y. J., Shay-El, Y., et al.: Quantification of dustforced heating of the lower troposphere, Nature, 395, 367-370, 1998.

Arimoto, R, Duce, R. A., Ray, B. J., et al.: Trace elements in the atmosphere over the north Atlantic, J. Geophys. Res., 100, 11991213, 1995.

Arimoto, R., Ray, B. J., Lewis, N. F., et al.: Mass-particle size distributions of atmospheric dust and the dry deposition of dust to the remote ocean. J. Geophys. Res., 102, 15867-15 874, 1997.

Arimoto, R.: Eolian dust and climate: relationships to sources, tropospheric chemistry, transport and deposition. Earth-Science Reviews, Vol. 54 (1-3), 29-42, 2001.

Bergametti, G.: African dust observed over Canary islands: Source regions identification and transport pattern for some summer situations, J. Geophys. Res., 94, 14, 855-14, 864, 1989.

Carlson, T. N. and Benjamin, S. G.: Radiative Heating Rates for Saharan Dust, J. Atmos. Sci., Jan., 193-213, 1980.

Chandra, S., Satheesh, S.K. and Srinivasan, J.: Can the state of mixing of black carbon aerosols explain the mystery of "excess" atmospheric absorption?, Geophys. Res. Lett., 31, doi:10.1029/2004GL020662, 2004.

Christopher, S. A., Wang, J., Ji, Q., et al.: Estimation of diurnal short wave dust aerosol radiative forcing during PRIDE, J. Goephys. Res., 108 (D19), art. no. 8596, 2003.

Chomette, O., Legrand, M., and Marticorena, B.: Determination of the wind speed threshold for the emission of desert dust using satellite remote sensing in the thermal infrared, J. Geophys. Res., 104, 31 207-31 215, 1999.

d'Almeida, G. A., Koepke, P., and Shettle, E. P.: Atmospheric Aerosols-Global Climatology and Radiative Characteristics, A. Deepak, Hampton, VA, 1991.

Deepshikha, S., Satheesh, S. K., and Srinivasan, J.: Regional Distribution of Absorbing Efficiency of Dust Aerosols over India and Adjacent Continents inferred using Satellite Remote Sensing, Geophys. Res. Lett., 32 (3), art. no. L03811, 1-4, 2005.

Duce, R. A.: The Atmospheric Input of Trace Species to the World Ocean, Global Biogeochem. Cycles, 5, 193-259, 1991.

Fitzgerald, J. W.: Marine Aerosols:A Review, Atmos. Environ., 25A, 533-545, 1991.

Gillette, D. A., Blifford, I. H., and Fryrear, D. W.: The Influence of Wind Velocity on the Size Distributions of Aerosols Generated by the Wind Erosion of Soils, J. Geophys. Res., 79, 4068-4075, 1974.

Gillette, D A.: Environmental factors affecting dust emissions by wind erosion, Saharan Dust, edited by: Morales, C., Wiley, 7194, 1979.

Ginoux, P., Prospero, J .M., Torres, O., and Chin, M.: Long-term simulation of dust distribution with the GOCART model: Correlation with the North Atlantic Oscillation, Environmental Modeling and Software, 19, 113-128, 2004.

Haywood, J., Francis, P., Osborne, S., Glew, M., Loeb, N., Highwood, E., Tanré, D., Myhre, G., Formenti, P., and Hirst, E.: Radiative properties and direct radiative effect of Saharan dust measured by the C-130 aircraft during SHADE: 1. Solar spectrum, J. Geophys. Res., 108(D18), 8577, doi:10.1029/2002JD002687, 2003.

Gong, S. L., Zhang, X. Y., Zhao, T. L., McKendry, I. G., Jaffe, D. A., and Lu, N. M.: Characterization of soil dust aerosol in China and its transport and distribution during 2001 ACE-Asia: 2. Model simulation and validation, J. Geophys. Res., 108, D9, 
doi:10.1029/2002JD002633, 2003.

Helgren, D. A. and Prospero, J. M.: Wind velocities associated with dust deflation events in the western Sahara, J. Climate Applied Meteorol., 26, 1147-1151, 1987.

Hess, M., Koepke, P., and Schult, I.: Optical properties of aerosols and clouds: The software package OPAC, Bulletin of Am. Meteorol. Soc., 79, 831-844, 1998.

Hsu, N. C., Tsay, S. C., King, M. D., et al.:Aerosol properties over bright-reflecting source regions, IEEE Trans. Geosci. Rem. Sens., 42(3), 557-569, 2004.

Junge, C. E.: Our knowledge of the Physico-Chemistry of aerosols in the undisturbed marine environment, J. Geophys. Res., 77, 5183-5200, 1972.

Kalu, A. E.: The African dust plume: its characteristics and propagation across West Africa in winter, in: Saharan Dust: Mobilisation, transport, deposition: papers and recommendations from a workshop held in Gothenburg, Sweden, 25-28 April 1977, edited by: Morales, C., Wiley, 1979.

Kaufman, Y. J., Tanré, D., Gordon, H. R., et al.: Passive remote sensing of tropospheric aerosol and atmospheric correction for the aerosol effect, J. Geophys. Res., 102 (D14), 16815-16830, 1997.

Kaufman, Y. J., Tanré, D., Dubovik, O., et al.: Absorption of sunlight by dust as inferred from satellite and ground-based remote sensing, Geophys. Res. Lett., 28 , 1479-1483, 2001.

Legrand, M.: The potential of infrared satellite data for the retrieval of Saharan-dust optical depth over Africa, J. Appl. Meteorol., 28, 309-319, 1989.

Legrand, M.: Thermal impact of Saharan dust over land, Part-II, Application to satellite IR remote sensing, J. Appl. Meteorol., 31, 181-193, 1992.

Leon, F. and Legrand, M.: Mineral dust sources in the surroundings of the north Indian Ocean, Geophys. Res. Lett., 30, 1309, doi:10.1029/2002GL016690, 2003.

Liao, H and Seinfeld, J. H.: Radiative forcing by mineral dust aerosols: sensitivity to key variables, J. Geophys. Res., 103, 31 637-31 645, 1998.

Martonchik, J. V.: Comparison of MISR and AERONET aerosol optical depths over desert sites, Geophys. Res. Lett., 31(16), L16102, 2004.

McTainsh, G. H.: Harmattan dust deposition in northern Nigeria, Nature, 286, 587-588, 1980

Miller, R. L. and Tegen, I.: Radiative forcing of a tropical direct circulation by soil dust aerosols, J. Atmos. Sci., 56 (14), 2403 2433, 1999.

Miller, R. L., Tegen, I., and Perlwitz, J.: Surface radiative forcing by soil dust aerosols and the hydrologic cycle, J. Geophys. Res., 109 (D4), art. no. D04203, 1-8, 2004.

Mohalfi, S., Bedi, H. S., and Krishnamurti, T. N, et al.: Impact of short wave radiative effects of dust aerosols on the summer season heat low over Saudi Arabia, Monthly Weather Rev., 126, 3153-3168, 1998.

Nickling, W. G. and Gillies, J. A.: Emission of dust from desert soils, in: Paleoclimatology and Paleometeorology: Modern and Past Patterns of Global Atmospheric Transport, edited by: Leinen, M. and Sarnthein, M., Kluwer, 133-165, 1989.
Prospero, J. M. : Dust in the Carribbean Atmosphere Traced to an African Dust Storm, Earth Planet. Sci. Lett., 9, 287-293, 1970.

Prospero, J. M.: African dust in America, Geotimes, 46(11), 24-27, 2001.

Prospero, J. M.: Global dust transport over the oceans: The link to climate, Geochimica Et Cosmochimica Acta, 67 (18), A384, 2003.

Prospero, J. M., Ginoux, P., Torres, O., et al.: Environmental characterization of global sources of atmospheric soil dust identified with the Nimbus 7 Total Ozone Mapping Spectrometer (TOMS) absorbing aerosol product, Rev. Geophys., (1), art. no. 1002, 122, 2002.

Ricchiazzi, P., Yang, S., Gautier, C., and Sowle, D.: SBDART, A research and teaching tool for plane-parellel radiative transfer in the Earth's atmosphere, Bull. Am. Meteorol. Soc., 79, 21012114, 1998.

Satheesh, S. K., Ramanathan, V., Jones, X. L., et al.: A Model for the natural and anthropogenic aerosols for the tropical Indian ocean derived from Indian ocean Experiment data, J. Geophys. Res., 104, D22, 27 421-27 440, 1999.

Satheesh, S. K. and Ramanathan, V.: Large differences in tropical aerosol forcing at the top of the atmosphere and earth's surface, Nature, 405, 60-63, 2000.

Seinfeld, J. H., Carmichael, G. R., Arimoto, R., et al.: Regional Climatic and Atmospheric Chemical Effects of Asian Dust and Pollution, Bull. Amer. Meteorol. Soc., 367-380, 2004.

Tanré, D., Kaufman, Y. J., and Holben, B. N.: Climatology of dust aerosol size distribution and optical properties derived from remotely sensed data in the solar spectrum, J. Geophys. Res., 106(D16), 18 205-18 217, 2001.

Tanré, D., Haywood, J., Pelon, J., et al.: Measurement and modeling of the Saharan dust radiative impact: Overview of the Saharan Dust Experiment (SHADE), J. Geophys. Res., 108(D18), 8574, doi:10.1029/2002JD003273, 2003.

Tegen, I. and Fung, I.: Modelling of Mineral Dust in the Atmosphere: Sources, Transport, and Optical Thickness, J. Geophys. Res., 99, 22 897-22 914, 1994.

Tegen, I. and Lacis, A. A.: Modeling of particle size distribution and its influence on the radiative properties of mineral dust aerosol, J. Geophys. Res.-A., 101 (D14), 19237-19244, 1996.

Tegen, I. and Miller, R. A.: General circulation model study on the inter-annual variability of soil dust aerosol, J. Geophys. Res., 103 (D20), 25 975-25 995, 1998.

Tegen, I., Hollrig, P., Chin, M., et al.: Contribution of different aerosol species to the global aerosol extinction optical thickness: Estimates from model results, J. Geophys. Res.-A., 102 (D20), 23 895-23 915, 1997.

Tegen, I., Werner, M., Harrison, S. P. and Kohfeld, K. E.: Relative importance of climate and land use in determining present and future global soil dust emission, Geophys. Res. Lett., 31, L05105, doi:10.1029/2003GL019216, 2004.

Zender, C. S., Bian, H., and Newman, D.: Mineral Dust Entrainment and Deposition (DEAD) model: Description and 1990s dust Climatology, J. Geophys. Res., 108(D14), 4416, doi:10.1029/2002JD002775, 2003. 